\title{
IDENTIFICACIÓN DE LOS ENCADENAMIENTOS MÁS PROMISORIOS DEL SECTOR AGROINDUSTRIAL DEL DEPARTAMENTO DEL QUINDÍO (COLOMBIA)*
}

\author{
ISABEL CRISTINA LONDOÑO FRANCO**, JUAN JOSÉ BOTERO VILLA*** \\ \& EDWIN TARAPUÉZ CHAMORRO***** \\ ESCUELA DE ADMINISTRACIÓN Y MERCADOTECNIA DEL QUINDÍO - EAM
}

Recibido/ Received/ Recebido: 21/07/2013 - Aceptado/ Accepted/ Aprovado: 30/03/2014

\begin{abstract}
Resumen
El propósito de este documento es identificar los encadenamientos más promisorios del sector agroindustrial en el departamento del Quindío (Colombia), examinando el marco de la política nacional y regional de productividad y competitividad, la información de fuentes secundarias y documentos referenciales. Se hizo un estudio correlacional, se revisaron, analizaron e interpretaron las variables (apuestas de encadenamientos productivos) halladas en las citadas unidades y se organizaron en matrices de convergencia que permitieran asociar temas comunes. Temas en los cuales se identificaron programas y estrategias enfocados a cinco encadenamientos en el departamento del Quindío: café, plátano, guadua, frutales de clima cálido y frío, y plantas aromáticas y medicinales.
\end{abstract}

Palabras clave: Agroindustria, Competitividad, Encadenamientos productivos.

\section{IDENTIFICATION OF THE MOST PROMISING CHAINS FOR AGRO INDUSTRY IN QUINDÍO (COLOMBIA)}

\begin{abstract}
This paper's purpose is to identify the most promising chains of agro-industry sector in Quindio (Colombia), examining national and regional political framework of productivity and competitiveness, secondary sources and reference documents information. A correlational study was conducted, the variables found in those units (productive chains) were reviewed, analyzed and interpreted and then organized into convergence matrices that allowed associating common issues. Topics in which pro-
\end{abstract}

\footnotetext{
El artículo es producto de la investigación "La asociatividad como alternativa de sostenibilidad de las cadenas de valor más promisorias del sector agroindustrial del departamento del Quindío" financiada por la Escuela de Administración y Mercadotecnia del Quindío EAM, 2009 - 2011.

* MSc en Administración de la Universidad Nacional de Colombia - Sede Manizales, Colombia. Directora del Centro de Investigación de la Escuela de Administración y Mercadotecnia del Quindío y Líder del Grupo de Investigación en Responsabilidad Social GRS de la misma institución. Correo electrónico: ilondono@eam.edu.co

*** Mg. en Derecho de la Empresa de la Universidad Pontificia de Comillas - Madrid, España. Especialización en Comercio Exterior de la Universidad Pontificia de Comillas - Madrid, España. Docente del Programa de Contaduría Pública de la Universidad del Quindío. Coinvestigador del Grupo de investigación GIGA de la Universidad del Quindío. Correo electrónico: jjbotero@uniquindio.edu.co

**** Doctorando en Ciencias Económicas (orientación Administración) de la Universidad Nacional de Córdoba - Córdoba, Argentina. Especialista en Alta Gerencia de la Universidad de Nariño - Nariño, Colombia. Docente de planta del Programa de Contaduría Pública de la Universidad del Quindío. Coinvestigador del Grupo de investigación GIGA de la Universidad del Quindío. Correo electrónico: eitarapuez@uniquindio.edu.co
} 
grams and strategies were identified and focused to five chains in Quindio: Coffee, banana, bamboo, fruit crops from warm and cold weather and aromatic and medicinal plants.

Keywords: Agro-industry, Competitiveness, Productivity Chains.

\title{
IDENTIFICAÇÃO DOS ENCADEAMENTOS MAIS PROMISSORES DO SETOR AGROINDUSTRIAL DO DEPARTAMENTO DE QUINDÍO (COLÔMBIA)
}

\begin{abstract}
Resumo
O propósito deste documento é identificar os encadeamentos mais promissores do setor agroindustrial no departamento de Quindío (Colômbia), examinando o marco da política nacional e regional de produtividade e competitividade, a informação de fontes secundárias e documentos referenciais. Fez-se um estudo correlacionado, revisaram-se, analisaram-se e interpretaram-se as variáveis (encadeamentos produtivos) encontradas nas unidades citadas e se organizaram em matrizes de convergência que permitissem associar temas comuns. Temas nos quais se identificaram programas $e$ estratégias enfocados a cinco encadeamentos no departamento do Quindío: café, plátano, bambu, frutas de clima quente e frio, e plantas aromáticas e medicinais.
\end{abstract}

Palauras chave: Agroindústria, Competitividade, Encadeamentos produtivos.

Londoño, I. Botero, J. \& Tarapuéz, E. (2014) Identificación de los encadenamientos más promisorios del sector agroindustrial del departamento del Quindío: un ejercicio en la competitividad regional. En: Revista de la Facultad de Ciencias Económicas de la Universidad Militar Nueva Granada. rev. fac.cienc.econ, XXII (1).

JEL: Q12, Q13, R59.

\section{Introducción}

Una de las ventajas competitivas más importantes del departamento del Quindío es el campo, su tradición y cultura cafetera. Estas condiciones le han permitido ser reconocido dentro de una de las regiones más representativas en este sector dentro del ámbito nacional e internacional, mediante la declaración, por parte de la UNESCO, del Paisaje Cultural Cafetero como patrimonio cultural de la humanidad. Sin embargo, las exigencias globales de internacionalización en las economías regionales o locales imponen fortalecer la producción de otros productos diferentes a los tradicionalmente producidos como el café. Capaces de ofrecer al departamento y a la región conurbada de la cultura cafetera, a sus familias y productores, nuevas oportunidades a partir de la identificación y focalización en ciertos productos agrícolas; productos a los cuales pueda incorporarse valor agregado y así tener la posibilidad de integrarse al mercado nacional e internacional, con productos diferenciados, innovadores y más competitivos, en el marco de la relación universidad empresa estado (UEE).

Partimos del concepto de competitividad como nivel de productividad de los recursos en un territorio que, a partir del conjunto de sus políticas, logra el crecimiento y desarrollo sostenido, confrontado en un mundo global. Seguimos aquí el concepto de competitividad de Michael Porter (2005), quien la plantea como la productividad con la que un país utiliza sus recursos humanos, económicos y naturales. Esta competitividad, expresa el mismo autor, comprende múltiples factores que facilitan el desarrollo de la misma, siendo uno de los principales la calidad del entorno empresarial microeconómico en el que compiten las empresas y en particular el desarrollo 
de políticas regionales que contribuyan a generar un territorio más competitivo.

Por ello, el propósito de este documento es ilustrar, en el marco de la política nacional y regional de productividad y competitividad, la información de fuentes secundarias y documentos referenciales que llevaron a precisar los encadenamientos más promisorios del sector agroindustrial en el departamento del Quindío. Estos documentos de política regional, se sintetizan en una Ilustración conclusiva que depura la información en términos de los referentes institucionales que precisan los principales productos y derivados en los que la región ha focalizado el ejercicio de su competitividad regional en el sector agrícola y agroindustrial.

A nuestro juicio, este enfoque puede ser un referente útil para otras regiones de nuestro país al momento de realizar ejercicios de especialización en la producción y focalización de esfuerzos exportadores de productos agrícolas o agroindustriales con vocación internacional, de cara a la incursión en mercados cada vez más globales, gracias a la suscripción por parte de Colombia de nuevos tratados de libre comercio y acuerdos de promoción y protección recíproca, y de eliminación de la doble tributación.

\section{Metodología}

Teniendo en cuenta la pregunta de investigación, ¿cuáles son los encadenamientos más promisorios del sector agroindustrial del departamento del Quindío? Se desarrolló una investigación de orden cualitativo que implicó, en primera instancia, la búsqueda, recolección, selección y estudio de fuentes secundarias definidas por los investigadores como las unidades de análisis, representadas en las agendas y políticas públicas departamentales y nacionales.

A partir de un estudio correlacional, se revisaron, analizaron e interpretaron las variables (apuestas de encadenamientos productivos) halladas en las citadas unidades y se organizaron en matrices de convergencia que permitieran asociar temas comunes. Temas en los cuales se identificaron programas y estrategias enfocadas a cinco encadenamientos en el departamento del Quindío: café, plátano, guadua, frutales de clima cálido y frío, y plantas aromáticas y medicinales. Este tipo de investigación permitió la convocatoria, por parte de la Secretaría de Agricultura y Desarrollo rural, Económico y Ambiental de la Gobernación del Quindío (Tabla 1), de las asociaciones que conforman tales encadenamientos. Esto, con el propósito de: (i) identificar en cada municipio cuáles eran sus apuestas productivas en términos de producción, comercialización y asociatividad; (ii) contrastar la realidad de las asociaciones con la intencionalidad de los programas y apuestas de las agendas y políticas analizadas; (iii) reflexionar acerca de las realidades de las asociaciones y la gestión gubernamental; (iv) conocer de primera mano la percepción de los productores con respecto a la política de gobierno enmarcada en el sector agroindustrial, e identificar sus prácticas culturales y sociales, así como su compromiso con el medio ambiente y sus expectativas en relación con la academia y el Estado.

Las unidades de análisis definidas para la investigación, representadas en las agendas y políticas públicas departamentales y nacionales, son: Sistema Nacional de Competitividad, Comisión Nacional de Competitividad (CNC), Plan Nacional de Desarrollo 2006, Plan Nacional de Desarrollo actual 20102014, Visión País 2019 y 2032, Acuerdos de Promoción y Protección Recíproca y de Inversión (APRI), Tratados de Libre Comercio (TLC), Programa de transformación productiva, Agenda Nacional de Competitividad, Agenda interna de productividad y competitividad, Agenda de Ciencia, Tecnología e Innovación 2006, Plan Regional de competitividad del Quindío 2009 y Planes de Desarrollo departamental del Quindío 2008 - 2011 y 2012 (Gobernación del Quindío, 2009).

Dichas unidades de análisis se organizaron en matrices de convergencia como instrumentos que facilitarían la interpretación de la información y la identificación tanto de apuestas productivas comunes, como de planes y estrategias que posteriormente se correlacionaron entre sí dando respuesta a la pregunta de investigación

Así mismo, mediante un autodiagnóstico conducido, se identificó en cada municipio el grado de asociatividad y relación con el gobierno y la academia. 
Este elemento constituye un componente decisivo en el fortalecimiento de la capacidad organizacional comunitaria y local, pues pone en las manos de la comunidad participante un método flexible, práctico y no condicionado; método que generó los insumos para el inicio de un segundo momento de la investigación.

Esta fase de la investigación ${ }^{1}$ tuvo dos momentos: el primero relacionado con la identificación de encadenamientos, base para la elaboración de este artículo y fundamento para el segundo momento, el cual no es objeto de esta publicación aunque los autores han considerado preciso citar. En un segundo momento se propuso identificar el grado de asociatividad de los actores que conforman los encadenamientos más promisorios del sector agroindustrial del departamento del Quindío a partir de cuatro componentes principales, a saber: compromisos éticos, ambientales, sociales, y relaciones con el gobierno y con la

Tabla 1. Asociaciones del sector agroindustrial del departamento del Quindío

\begin{tabular}{|c|c|c|c|c|c|}
\hline Municipio & Plátano & $\begin{array}{c}\text { Frutales } \\
\text { de clima } \\
\text { frío y } \\
\text { cítricos }\end{array}$ & $\begin{array}{c}\text { Hierbas } \\
\text { aromáticas } \\
\text { y medici- } \\
\text { nales }\end{array}$ & Guadua & Café \\
\hline Armenia & 1 & 1 & 1 & 2 & 1 \\
Buenavista & 3 & 3 & - & - & 1 \\
Calarcá & 6 & 3 & 3 & 1 & 1 \\
Circasia & - & 5 & - & - & 2 \\
Córdoba & 6 & 6 & - & 1 & 4 \\
Filandia & - & 2 & - & - & 2 \\
Génova & - & 4 & 1 & - & 3 \\
Montenegro & 2 & 1 & - & - & 2 \\
Pijao & 1 & 4 & - & - & - \\
Quimbaya & 1 & - & 3 & - & - \\
Salento & 1 & 1 & 1 & - & - \\
La Tebaida & 1 & 1 & 1 & - & - \\
\hline Total & 22 & 31 & 9 & 4 & 16 \\
\hline
\end{tabular}

academia; en cada uno de los cuales se diseñaron estrategias de mejoramiento como aporte a la competitividad del sector.

\section{Entorno geográfico}

El departamento del Quindío se encuentra localizado en la zona Centro Occidente del país (flanco occidental de la Cordillera Central), con una superficie que abarca una extensión de $1.961 .830 \mathrm{~km}^{2}$ y con una población de 518.691 habitantes (Dane, 2005 citado por Gobernación del Quindío, 2009a). Su ubicación geollustración hace del Quindío un territorio con importantes ventajas competitivas, entre las que destacan su diversidad climática, el acceso a la infraestructura de transporte terrestre, aéreo y marítimo del Occidente colombiano, así como su gran biodiversidad e identidad cultural, que finalmente sirvieron de base para ser parte de la zona declarada patrimonio cultural de la humanidad por la UNESCO en junio del 2011. Entre las características biofísicas principales del Quindío se encuentran: (i) Pertenencia a la cuenca hidrollustración del Río La vieja, (ii) presenta dos zonas morfológicas claras, una de montaña, correspondiente a la cordillera central, y otra de piedemonte o zona plana y (iii) diversidad de pisos climáticos (desde los $1180 \mathrm{msnm}$ en La Tebaida, hasta los 4500 msnm en el Parque de los Nevados) y presencia de variados tipos de paisaje.

En el ámbito regional, la articulación que posee el Quindío en el marco del Eje cafetero, se basa fundamentalmente en su sistema de ciudades entre capitales y municipios adyacentes que conforma una red que entrelaza flujos y nodos funcionales con características particulares y que se estructuran en el cruce de dinámicas importantes de orden nacional generando una verdadera connurbación entre las mismas; complementariedad en la prestación de servicios y vocaciones territoriales de sus municipios con gran movilidad de su población que constituye su recurso humano, clave en la competitividad regional. Estas dinámicas son en gran medida facilitadas por

Londoño \& Sánchez (2009), donde se plantea la asociatividad como alternativa de sostenibilidad en los encadenamientos más promisorios del sector agroindustrial del departamento del Quindío (2009 - 2011).

2 Fuente: Londoño \& Sánchez (2009). 
la alta densidad poblacional, el flujo migratorio entre ellos y la cercanía entre centros poblados, por lo cual sus problemáticas son comunes y las soluciones se deben plantear de manera concertada y sistémica y donde la región tiene grandes retos (Gobernación del Quindío, 2009a).

\section{4. Áreas para la producción agrícola y ganadera y de explotación de recursos naturales}

Comprende terrenos que deben ser mantenidos y preservados por su destinación a usos agrícolas, ganaderos, forestales o de explotación de recursos naturales ${ }^{3}$; en el caso del uso forestal, la zonificación de las áreas por aptitud forestal comercial para el departamento del Quindío, de acuerdo a lo expedido por la Corporación Autónoma Regional de Quindío (CRQ, 2004), está distribuida de la siguiente manera: zonas de aptitud forestal en Áreas (Hectáreas): comercial sin restricciones 32.226,07, comercial con restricciones menores $17.909,932$, protectoras productoras $29.304,737$, protectoras productoras guadua mixta $18.966,391$, productora guadua $17.569,248$, protectoras $50.318,345$, para restauración de ecosistemas $16.394,916$ y de exclusión a plantaciones forestales 9.490,158.

Las áreas de producción agrícola sin restricciones se destinan a la producción de especies agrícolas, incluyendo cultivos limpios y semilimpios, dadas las condiciones de los suelos y tienen los siguientes usos (CRQ, 2010): (i) usos permitidos: cultivos permanentes o transitorios, limpios y semilimpios, cultivos densos y demás procesos productivos; (ii) usos limitados: siembras consecutivas tanto de yuca como de cultivos semestrales, uso indiscriminado de agroquímicos y plantaciones forestales; (iii) usos incompatibles: turismo, minería y otras actividades que limiten o interfieran en su capacidad para la generación de alimentos.
Dentro de las áreas de producción agrícola se incluyen los suelos que según la clasificación del Instituto Geográfico Agustín Codazzi (IGAC) pertenezcan a las clases I, II y III, y aquellos correspondientes a otras clases agrologicas que sean necesarias para la conservación de los recursos de aguas, control de procesos erosivos y zonas de protección forestal ${ }^{4}$. La Clase II - subclase Ile (3.812 has) son aptos para producir toda clase de cultivos tecnificados propios de clima medio, húmedo; subclase Ilec (876 has) en él se pueden producir todos los cultivos de clima medio, húmedo transicional a medio seco. Clase III subclase IIlec (20.600 has) aptos para toda clase de cultivos tecnificados de clima medio, húmedo; subclase IIle (sin características); subclase IIlec (9.572 has) aptos no solo para toda clase de cultivos tecnificados de clima medio, húmedo transicional al medio y seco, sino también para la ganadería intensiva con pastos mejorados, evitando sobrepastoreo; subclase IIIsh (4.434 has), cuando estos suelos se encuentran en clima medio y húmedo, son aptos para cultivos agrícolas. También son aptos para ganadería intensiva con pastos mejorados de corte y pastoreo, evitando la sobrecarga de ganado con el fin de controlar el pisoteo excesivo.

Las áreas de producción agrícola con restricciones son aquellas destinadas a la actividad productiva agrícola donde se deben adelantar prácticas de manejo y conservación de suelos y establecimiento de cultivos densos y asociados para evitar la degradación del suelo y demás recursos relacionados (CRQ, 2010). Los tipos de usos de estas áreas son (i) Usos permitidos: establecimiento de bosques nativos $y$ guaduales, sistemas estabulados de ganadería intensiva para leche, coberturas vegetales en cítricos y arborización de cafetales que se encuentran a libre exposición, sistemas agroforestales; (ii) Usos limitados: cultivos limpios y semilimpios con prácticas de conservación de suelos, ganaderías intensivas con sistemas de semiestabulación, plantaciones fo-

3 De conformidad con lo dispuesto en el parágrafo del artículo $3^{\circ}$ del Decreto 097 de 2006 (Por el cual se reglamenta la expedición de licencias urbanísticas en suelo rural y se expiden otras disposiciones), en estos terrenos no podrán autorizarse actuaciones urbanísticas de subdivisión, parcelación o edificación de inmuebles que impliquen la alteración o transformación de su uso actual (CRQ, 2010).

4 Según estudios a escala 1:100.000 realizados por el Instituto Geográfico Agustín Codazzi, en el Departamento del Quindío, no existen suelos clase I (CRQ, 2010) 
restales comerciales, sistemas agrosilvopastoriles y (iii) Usos incompatibles: ganadería intensiva (leche y carne) y cultivos limpios.

La Corporación concluye la descripción del espacio geográfico del Quindío, relacionado con la actividad agrícola; "la zonificación agropecuaria sugerida tiene como objetivo la demarcación de las tierras con vocación y limitaciones similares y de acuerdo a esto recomendar el uso más adecuado y acorde con sus posibilidades" (CRQ, 2010). Las unidades de uso agrícola se clasifican en: (i) áreas para cultivos tecnificados (café, plátano, caña panelera, frijol y frutales), ocupan una extensión de 41.241 has y se localizan principalmente alrededor de los municipios de Armenia, Montenegro y Quimbaya; (ii) áreas para cultivos de frutales y en algunos sectores cultivos de café, tienen una extensión de 11.238 has y se localizan en una franja desde el municipio de Buenavista hasta el municipio de Calarcá; (iii) las áreas de cultivos de semibosque, especialmente café con sombrío, plátano y frutales, ocupan una extensión de 12.793 has y se localizan desde el municipio de Génova hasta los municipios de Buenavista y Pijao; (iv) áreas para cultivos tecnificados de caña panelera, sorgo, frijol, tomate, pimentón y frutales, tienen una extensión de 13.708 has y se localizan más arriba de la confluencia de los ríos Barragán y Quindío hacia el norte, municipios de Calarcá, La Tebaida y Pijao.

\section{Agendas y políticas públicas departamentales y nacionales}

\subsection{Perspectiva de la Política Nacional}

La política regional de productividad y competitividad se enmarca dentro de una serie de lineamientos de orden institucional presentes en el Sistema Nacional de Competitividad, y definido en el artículo segundo del Decreto 2828 de 2006 como: "El conjunto de orientaciones, normas, actividades, recur- sos, programas e instituciones públicas y privadas que prevén y promueven la puesta en marcha de una política de productividad y competitividad". Su máximo órgano es la Comisión Nacional de Competitividad (CNC), de la cual -como expresión de un ejercicio solidario y mancomunado- hacen parte el sector público y privado, las empresas, la academia, las organizaciones laborales y las regiones, dentro de estas el departamento del Quindío, en las cuales se replica dicho modelo de participación conjunta y diversa en congruencia con las particularidades de cada una de ellas.

Este ejercicio parte de una visión de largo plazo, en la que se buscó armonizar los lineamientos del Plan Nacional de Desarrollo 2006-2010 "Estado Comunitario: desarrollo para todos", también incluida en el Plan Nacional de Desarrollo actual 2010-20145: "Prosperidad para todos", la Visión País 2019 y 2032, las políticas sectoriales y el marco de mediano plazo (MGMP), del cual se derivaron tres objetivos estratégicos misionales y dos objetivos transversales de apoyo: internacionalización de la economía, transformación productiva y Colombia destino turístico de clase mundial; Comunicación e imagen y gestión del desempeño.

Los dos primeros objetivos tienen relación directa con nuestro objeto de la investigación. En efecto, el primer objetivo busca abrir a Colombia a los mercados mundiales, con avances importantes en la internacionalización de su economía y, en el cual, el país pasó de dos tratados comerciales con cinco países en 2002 a tener hoy por hoy un número importante de Acuerdos de Promoción y Protección Recíproca y de Inversión (APRI), al igual que en Tratados de Libre Comercio (TLC), según se advierte en las Ilustración s siguientes, que en el 2014 nos darán un acceso preferencial a más de mil quinientos millones de consumidores en diversos puntos del planeta (Tabla 2).

\footnotetext{
"Prosperidad para todos": "El desarrollo de una política exterior integral para Colombia implica la necesidad de: (i) consolidar la inserción y relevancia internacional del país, para lo cual es clave implementar los TLC con Canadá, EFTA, Estados Unidos y la Unión Europea; (ii) afianzar los vínculos con América Latina y el Caribe; (iii) desarrollar estrategias de inserción activa en el Asia-Pacífico." (Plan Nacional de Desarrollo 2010-2014, 672).
} 
Ilustración 1. Sistema Administrativo Nacional de Competitividad ${ }^{6}$

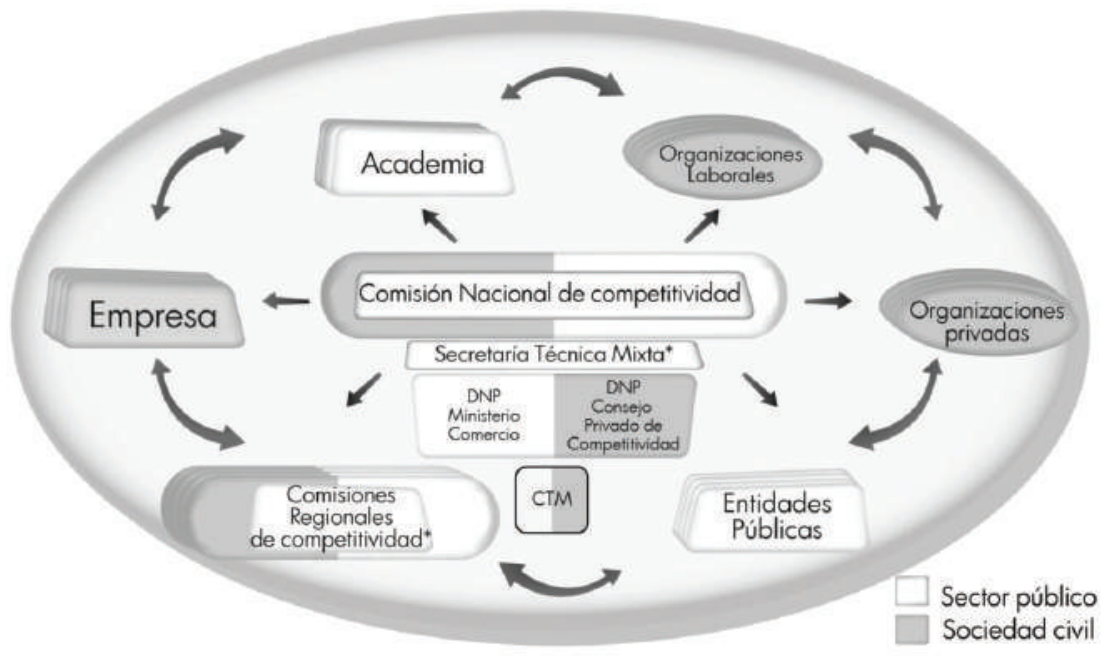

Así mismo, Colombia avanzó en varios acuerdos de inversión y acuerdos para evitar la doble tributación (ADTs) con diferentes países y bloques comerciales tales como España, Chile, Canadá, México, Suiza y la CAN -en negociación: Alemania, Países Bajos, India, Bélgica, Corea, República Checa, Japón y Francia-, lo cual resulta decisivo, pues el acceso a mercados más globalizados es una de las condiciones necesarias para el fortalecimiento de los sectores de clase mundial; razón por la cual es importante seguir avanzando en las acciones y directrices tendientes a su consolidación y continua expansión (Wong, 2005).

La velocidad en este ejercicio de integración ha sido siempre un tema de discusión por parte de los empresarios e incluso por algunos académicos. Lo cierto es que a la fecha muchos de nuestros países vecinos -con incrementos sostenidos en el PIB Nacional- lo han hecho más rápido y eficientemente que nosotros. A continuación, un Ilustración comparativo (Ilustración 2) muestra cómo han avanzado en su apertura de mercados a otros países algunos de nuestros vecinos que han adoptado el libre comercio como estrategia de crecimiento y desarrollo económico.
En relación con el segundo objetivo, "La transformación de la estructura productiva", desde el Gobierno Nacional se avanza en un programa que lleva este mismo nombre, "Programa de transformación productiva", liderado por el Ministerio de Comercio, Industria y Turismo -en coordinación con el Consejo Privado de Competitividad Nacional y demás entidades del sector- mediante el cual se están implementando doce planes priorizados de negocios entre sectores industriales y agrícolas a través de un modelo de desarrollo económico sectorial, en alianza público - privada, con metodología, lenguaje común y metas concertadas y con creciente visibilidad nacional $e$ internacional (Ministerio de Comercio, Industria y Turismo, 2012). En el tema de los encadenamientos productivos de carácter agroindustrial están los cuatro sectores del agro que han formulado sus planes de negocios: camaronicultura, chocolatería, confitería y sus materias primas; carne bovina, palmas, aceites y grasas vegetales. Sectores que se reflejan en el más reciente documento denominado: Agenda Nacional de Competitividad; y se enuncian en el Informe nacional de competitividad - Ruta a la prosperidad colectiva $2011-2012$.

\footnotetext{
6 Fuente: Elaborada a partir del Sistema Nacional de Competitividad Colombia (Valencia, 2008).
} 
Tabla 2. Acuerdos de promoción y protección recíproca $\mathrm{APRIS}^{7}$

\begin{tabular}{|c|c|c|c|c|}
\hline \multirow{3}{*}{$\begin{array}{c}\text { Países con } \\
\text { acuerdos } \\
\text { Total }\end{array}$} & \multicolumn{4}{|c|}{ Población } \\
\hline & \multicolumn{4}{|c|}{ Millones de personas } \\
\hline & 2011 & 2012 & 2013 & 2014 \\
\hline Comunidad Andina & 55,6 & 56,5 & 57,4 & 58,4 \\
\hline Venezuela & 29,8 & 30,4 & 31,0 & 31,6 \\
\hline Mercosur & 245,7 & 247,9 & 249,9 & 251,9 \\
\hline Chile & 17,4 & 17,6 & 17,8 & 18,0 \\
\hline México & 109,7 & 110,8 & 111,9 & 113,0 \\
\hline Triángulo del Norte & 28,8 & 29,4 & 29,9 & 30,5 \\
\hline Canadá & 34,4 & 34,7 & 34,9 & 35,2 \\
\hline Suiza y Liechtenstein & 7,8 & 7,9 & 7,9 & 8,0 \\
\hline Noruega & & 5,0 & 5,1 & 5,1 \\
\hline Estados Unidos & & 315,9 & 318,9 & 321,9 \\
\hline Unión Europea & & & 502,7 & 503,7 \\
\hline Panamá & & & 3,7 & 3,7 \\
\hline Islandia & & & 0,3 & 0,3 \\
\hline Corea del Sur & & & & 49,3 \\
\hline Turquía & & & & 73,8 \\
\hline Israel & & & & 7,9 \\
\hline $\begin{array}{c}\text { Total con acuerdos } \\
\text { vigentes }\end{array}$ & 529,3 & 856,0 & $1.71,5$ & $1.512,3$ \\
\hline
\end{tabular}

Ilustración 2. Acuerdos comerciales vigentes $2012^{8}$
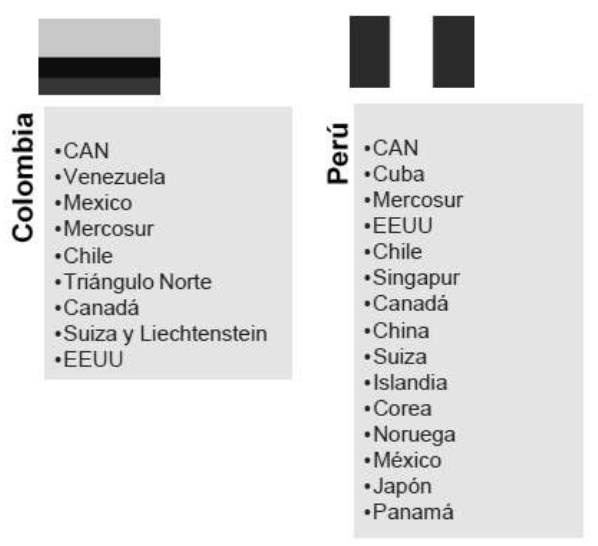

Fuente: Elaborada a partir de Díaz (2012).

8 Fuente: Díaz (2012).
"Los sectores dentro del Programa de Transformación Productiva están divididos en tres olas. Una primera ola de sectores conocida como "más y mejor de lo bueno" que incluye: Autopartes; Industria Ilustración ; Energía Eléctrica y Bienes y Servicios Conexos; y Textil, Confecciones y Moda. Una segunda ola conocida como "sectores nuevos y emergentes" que incluye: Software; BPO\&O (Servicios Tercerizados y a Distancia); Turismo de Salud; y Cosméticos y Artículos de Aseo. La tercera ola la constituyen los siguientes sectores del ámbito agropecuario y agroindustrial: Camaronicultura; Cacao, Chocolatería y Confitería; Palma y Aceites y Grasas; y Carne Bovina" (Consejo Privado de Competitividad Colombia, 2011).

Los objetivos de internacionalización y de transformación productiva se alimentan transversalmente mediante el fortalecimiento de la presencia regional, especialmente a través de treinta y cinco comisiones regionales de competitividad con sus iniciativas de proyectos formuladas y priorizadas al interior de los respectivos Planes regionales de competitividad en cada una de ellas; lo cual es una clara expresión de una alianza público-privada que apoya la competitividad y productividad desde las regiones, pues,
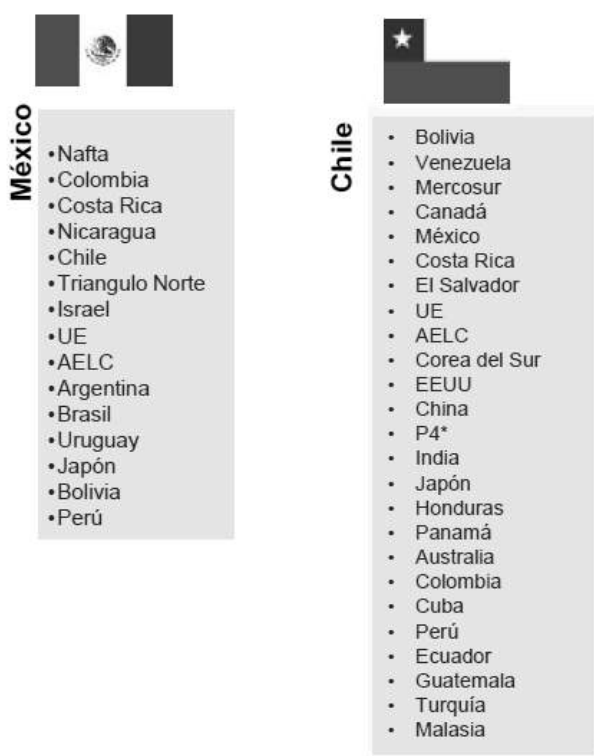
ciertamente, una estrategia nacional de competitividad nace precisamente en las regiones donde las empresas desarrollan sus actividades productivas de "coordinación entre las órbitas nacional y regional, porque es precisamente aquí donde las empresas desarrollan sus actividades" (Conpes 3668, 2008, 6).

Así mismo, los objetivos estratégicos nacionales -muchas veces replicados al interior de las regiones- se impulsan a través del estímulo a los objetivos transversales tales como la ciencia, innovación y tecnología; educación para la productividad y competitividad -en criterios de calidad, pertinencia y cobertura-; infraestructura y formulación y seguimiento de la política pública articulada con el sector empresarial y la academia.

\subsection{Planes de desarrollo nacional y agendas departamentales}

El análisis de los encadenamientos promisorios del sector agroindustrial, parte de varias y diversas fuentes secundarias, principalmente el Plan de Desarrollo Departamental ajustado (Ordenanza 002 de marzo 2 de 2009), la Agenda interna de productividad y competitividad, la Agenda de Ciencia, Tecnología e Innovación 2006, el Plan Regional de competitividad del Quindío 2009, en concordancia con algunas directrices consignadas en documentos oficiales acordes con la política nacional que tiene el mismo Ministerio de Agricultura y Desarrollo rural, entre otros, donde se identifican los encadenamientos más promisorios en el sector agroindustrial regional, objeto de este artículo. A continuación un breve desarrollo de los mismos.

\subsubsection{Planes de desarrollo departamental del Quindío: 2008-2011 "Quindío unido" y 2012-2015 “Quindío para todos"}

Dentro del programa de sostenibilidad y competitividad del Plan de desarrollo departamental 2008 - 2011, el gobierno local definió los sectores promisorios en la producción agrícola y agropecuaria, así como las prioridades de inversión rural. La prioriza- ción procuró generar mayor impacto en la calidad de vida de sus habitantes y fortalece el sector rural. Para ello se inició el ejercicio participativo en enero de 2009, donde se definió la priorización de actividades agropecuarias e inversión en el sector rural por municipio (Tabla 3). Para el caso de este estudio el análisis se delimitó en el ámbito agrícola, sin desconocer la importancia que las actividades productivas pecuarias aportan al departamento.

Tabla 3. Encadenamientos del sector agroindustrial definidos por el gobierno departamental ${ }^{9}$

\begin{tabular}{|l|l|}
\hline \multicolumn{1}{|c|}{ Municipio } & \multicolumn{1}{|c|}{\begin{tabular}{c}
\multicolumn{1}{c|}{\begin{tabular}{c}
\multicolumn{1}{c|}{ agrícola y agropecuaria } \\
Armenia
\end{tabular}} \\
\hline Filandia \\
mortalizas para abastecimiento, porcicultura y
\end{tabular}} \\
\hline Pijao & $\begin{array}{l}\text { Alianzas ganaderas, Mejoramiento genético y de } \\
\text { infraestructura, Centros de distribución de los con- } \\
\text { centrados }\end{array}$ \\
\hline Buenavista & Seguridad alimentaria \\
\hline Circasia & $\begin{array}{l}\text { Mora, plátano, Centro de acopio, banco de semi- } \\
\text { Ilas }\end{array}$ \\
\hline Córdoba & $\begin{array}{l}\text { Seguridad alimentaria para consumo, Bancos de } \\
\text { proteína para ganadería, Mejoramiento de infraes- } \\
\text { tructura para caficultura }\end{array}$ \\
\hline Génova & $\begin{array}{l}\text { Huertas caseras, desarrollo agroindustrial, proce- } \\
\text { sos empresariales y porcicultura }\end{array}$ \\
\hline Salento & $\begin{array}{l}\text { Porcicultura, ganadería, Seguridad alimentaria, } \\
\text { Ruedas de negocio y Torrefactora de café }\end{array}$ \\
\hline Quimbaya & Ganadería y mora \\
\hline Montenegro & $\begin{array}{l}\text { Caña panelera, Sanidad vegetal en la Vereda Troca- } \\
\text { deros, Alianza productiva de la guadua }\end{array}$ \\
\hline La Tebaida & Plátano y piscicultura \\
\hline Calarcá & No asistió \\
\hline
\end{tabular}

Así mismo, el Plan de Desarrollo 2008-2011 se proyectó con miras al fortalecimiento de los subprogramas abajo relacionados, soportados en una plataforma de agroindustria como factor de desarrollo. El análisis de los subprogramas y sectores promisorios permitió identificar encadenamientos del sector agroindustrial, los cuales se convirtieron, en 2009,

\footnotetext{
9 Fuente: Gobernación del Quindío - Boletín Quindío (2009a).
} 
en insumos para la identificación de encadenamientos promisorios del sector agroindustrial del departamento del Quindío (Tabla 4), así:

- Subprograma de sistemas productivos promisorios agropecuario, forestal y minero: De acuerdo con la vocación agropecuaria, el gobierno departamental en este punto busca apoyar el uso de semillas de alta calidad y especies mejoradas en los cultivos de caña, cítricos, frutales de clima frío y cálido, hierbas aromáticas y medicinales, flores y follajes exóticos, hortalizas, verduras y granos.

- Subprograma de cadenas productivas agropecuarias: El establecimiento de convenios en el marco de agricultura por contrato busca integrar las asociaciones en el programa en desarrollo del principio de asociación, en aras de aumentar el volumen de comercialización de la producción, con asistencia técnica a los productores para que mejoren sus productos a través del manejo de tecnologías limpias y consolidar cinco cadenas productivas agropecuarias (café especial, caña panelera, plantas medicinales, aromáticas y condimentarías, lácteos y cárnicos); así como suscribir convenios y/o alianzas de cooperación interinstitucionales, gubernamentales e internacionales para la asistencia técnica agrícola (mejoramiento genético y repoblamiento).
- Subprograma de agroindustria factor de desarrollo: Apoya al sector agroindustrial y empresas que lo integran, para incorporar procesos eficientes de producción mediante la transferencia de tecnología. Igualmente se promueve el equipamiento y puesta en marcha de un centro de desarrollo tecnológico o la adhesión a uno ya existente.

El gobierno actual (Gobernación del Quindío, 2012, 113) propone estrategias de fortalecimiento en el agro en concordancia con el Plan Regional de Competitividad Quindío 2032 y sectores de clase mundial, donde la coincidencia con los mismos radica en el manejo del elemento teleológico para abordar el sector agropecuario regional, más que en la identificación de las actividades promisorias y encadenamientos ya precisados en el plan anterior. En este sentido, el mencionado plan propone que este sector sea:

"Uno de los cinco sectores con alto potencial de crecimiento que impulsarán el desarrollo económico del país, por medio de la contribución al Producto Interno Bruto, la generación de empleo y de divisas por las exportaciones del agro y la capacidad productiva del campo colombiano para generar empleo e ingresos para la población rural, incrementar la competitividad de la producción, ampliar y diversificar el

Tabla 4. Encadenamientos productivos promisorios identificados en el Plan de Desarrollo departamental del Quindío $2008-2011^{10}$

\begin{tabular}{|c|c|c|c|c|c|c|c|}
\hline \multirow{2}{*}{ Programas relevantes } & \multicolumn{7}{|c|}{ Plan de Desarrollo departamental } \\
\hline & \multicolumn{7}{|c|}{ Encadenamientos identificados } \\
\hline $\begin{array}{l}\text { Subprograma de sistemas producti- } \\
\text { vos promisorios agropecuario, fores- } \\
\text { tal y minero }\end{array}$ & Caña & Cítricos & $\begin{array}{l}\text { Frutales de } \\
\text { clima frío y } \\
\text { cálido }\end{array}$ & $\begin{array}{l}\text { Hierbas } \\
\text { aromáticas y } \\
\text { medicinales }\end{array}$ & $\begin{array}{l}\text { Flores y } \\
\text { follaje }\end{array}$ & $\begin{array}{c}\text { Hortalizas y } \\
\text { verduras }\end{array}$ & Granos \\
\hline $\begin{array}{l}\text { Subprograma de cadenas productivas } \\
\text { agropecuarias, se soportará en el } \\
\text { marco de agricultura por contrato }\end{array}$ & $\begin{array}{c}\text { Cafés } \\
\text { especiales }\end{array}$ & Plátano & Guadua & $\begin{array}{l}\text { Flores y } \\
\text { follaje }\end{array}$ & Lácteos & Cárnicos & \\
\hline $\begin{array}{l}\text { Subprograma de agroindustria factor } \\
\text { de desarrollo }\end{array}$ & \multicolumn{7}{|c|}{$\begin{array}{l}\text { Será la plataforma para que los dos subprogramas arriba mencionados se puedan consolidar (al menos 9) } \\
\text { con valor agregado, mediante transferencia tecnológica, construcción de un Centro de Desarrollo Tecnoló- } \\
\text { gico y creación de Incubadoras de Empresas }\end{array}$} \\
\hline
\end{tabular}

10 Fuente: Gobernación del Quindío (2009a). 
mercado interno y externo, equidad en el desarrollo regional y la gestión del riesgo agropecuario" (Gobernación del Quindío, 2012).

\subsection{Un referente nacional: los encadenamientos del sector agroindustrial por el Ministerio de Agricultura y Desarrollo Rural - MADR}

El Plan de Desarrollo Departamental 2012-2015 "Gobierno firme por un Quindío más humano", establece en el Subprograma 2 "Competitividad rural": "Apoyar y fortalecer procesos de encadenamiento productivo departamental y regional enmarcados dentro de las cadenas productivas reconocidas por el Ministerio de Agricultura y Desarrollo rural". Esto, con el propósito de fortalecer al 2015 los encadenamientos productivos, enmarcados en lo dispuesto por dicho ministerio.

Desde el sector público, tanto nacional como departamental, se enfatiza en el concepto de encadenamiento productivo antes que en el producto mismo. $\mathrm{Y}$ es que las cadenas productivas son actualmente una estrategia regional para hacer frente a la competitividad global (Diez, 2003); como quiera que nos permite ser diferentes en la globalización y poder manejar mejor el mercadeo territorial de carácter local.

El impacto de la política pública en la formación de las cadenas productivas, y de éstas en el mundo empresarial y la competitividad global ha sido alto dado que favorece la consolidación de las mismas a partir de una mejor articulación entre los actores con la creación de mejores condiciones de inversión que favorezcan la productividad y competitividad de los mismos (Gobernación del Quindío, 2009b, 34), las cuales se ven favorecidas por procesos innovadores (Grobart, 2003).

Colombia no es la excepción, y desde las funciones asignadas por el MADR a la Dirección de Cadenas Productivas está coordinar la ejecución de la política sectorial en los procesos y cadenas productivas del sector agropecuario y rural cuyos principales encadenamientos productivos, según los resultados de nuestra investigación, son:
- Cadena de los cítricos: Dentro de los seis núcleos o capítulos regionales, el de Occidente, al que pertenece el Quindío tiene como propósito fortalecer y modernizar la cadena productiva de los cítricos en Colombia con miras a aprovechar plenamente las oportunidades en los mercados internos y externos. Se suma a ella la cadena de la mora, impulsada dentro de las regiones del país en las cuales se encuentra el Quindío. Y complementa este grupo la cadena de las pasifloras (Gulupa, Granadilla y Maracuyá), presente en el Eje Cafetero y constituida por los representantes de los siguientes eslabones: proveedores de insumos, productores, comercializadores mayoristas, comercializadores minoristas, industrias y sector exportador, así como las entidades de apoyo.

- Cadena guadua y su industria: La cadena priorizó nueve departamentos, entre ellos Quindío, los cuales presentan mayor potencialidad para el desarrollo de esta actividad productiva. Los departamentos del Eje Cafetero representan el $60 \%$ de la producción nacional y de la generación de valor agregado en la producción de paneles laminados para la industria y en las líneas de negocios de construcción, fabricación de muebles para el jardín, hogar y oficinas, accesorios y artesanías. Como resultado de las convocatorias del Ministerio de Agricultura y de alianzas Gobierno-Universidad-Empresa, en los últimos cuatro años la cadena de la guadua ha logrado avances significativos en investigación y desarrollo tecnológico en sistemas constructivos con guadua y en el desarrollo de productos cosméticos y farmacéuticos a partir de los subproductos (del vinagre de guadua y de las hojas de la guadua).

- Cadena de plantas aromáticas: Se encuentra en proceso de estructuración. Este cultivo se ha convertido en un importante componente del ingreso de la población rural, especialmente de pequeños y medianos productores y grupos de mujeres; por lo tanto, esta cadena productiva sirve como escenario para diseñar estrategias encaminadas a proteger este subsector productivo naciente y a prepararlo para insertarse en 
los nuevos escenarios de comercialización, los cuales se están generando bajo las expectativas de una potencial exportación a países de economías desarrolladas.

- Cadena del plátano: En el año 2015 la cadena productiva de plátano en Colombia comenzará transformaciones sustantivas en materia de productividad y competitividad, llevando su rendimiento de 7,3 a 10,0 toneladas por hectárea, los costos de producción reducidos en un $5 \%$, el área de producción alcanzará la 600.000 hectáreas con una producción de 6.024 .000 toneladas y con un incremento del $4 \%$ al $10 \%$ de la producción destinadas al comercio internacional, con procesos de investigación y mejoramiento genético como soporte fundamental de estos propósitos.

En el año 2025 la cadena productiva de plátano en Colombia habrá alcanzado el más alto grado de productividad y competitividad, alcanzando un rendimiento de doce toneladas por hectárea, habiendo reducido los costos de producción en un $10 \%$, estabilizado el área sembrada en 750.000 hectáreas, destinado el $12 \%$ de su producción a los mercados internacionales y mejorado considerablemente las condiciones de vida y de trabajo de los productores.

\subsection{Agenda interna para la productividad y competitividad del Quindío}

La Agenda interna consistió en un plan de acción conjunto entre la Nación, las entidades territoriales, el sector privado, los actores políticos y la sociedad civil, cuyo objetivo fue identificar, con base en una visión de futuro nacional y regional, las áreas fundamentales en las cuales resultaba prioritario adelantar acciones de corto, mediano y largo plazo para mejorar la productividad y la competitividad del país. Fue un tipo de planeación participativa de "base" que apuntó a una integración horizontal concertada, donde las regiones se proyectaron a sí mismas hacia el futuro, dando relevancia al ideal en que quisieran convertirse para enfrentar los retos de la internacio- nalización de la economía, en el marco de un proceso de concertación y diálogo con las regiones y los sectores productivos, en tres dimensiones básicas: regional, sectorial y transversal.

Esta agenda pretendió recoger las estrategias de desarrollo económico regional y la ampliación de las oportunidades comerciales para el país frente a los retos que nos exigen los mercados internacionales, cada vez más ampliados. Las acciones de la agenda interna en el departamento del Quindío se concentraron en las siguientes apuestas productivas (Tabla 5).

Tabla 5. Apuestas productivas de la agenda interna de productividad y competitividad $^{11}$

\begin{tabular}{|c|c|}
\hline Sector & Apuestas productivas Agenda Interna \\
\hline Agroindustria & $\begin{array}{l}\text { Conformar y consolidar la cadena agroindustrial con én- } \\
\text { fasis en producción limpia y buenas prácticas de manu- } \\
\text { factura y trazabilidad para mercados internacionales }\end{array}$ \\
\hline & Cuero y productos (marroquinería) \\
\hline Manufacturas & $\begin{array}{l}\text { Conformar y articular la cadena de confecciones, marro- } \\
\text { quinería y artesanías implementando una estrategia de } \\
\text { diferenciación de producto y dirigida al mercado inter- } \\
\text { nacional }\end{array}$ \\
\hline Educación & $\begin{array}{l}\text { Creación y consolidación de un complejo de conoci- } \\
\text { miento de excelencia con un enfoque local articulado a } \\
\text { dinámicas internacionales }\end{array}$ \\
\hline Software & $\begin{array}{l}\text { Conformar y articular la cátedra de software para suplir la } \\
\text { demanda nacional e internacional }\end{array}$ \\
\hline Turismo & $\begin{array}{l}\text { Conformar la cadena de turismo con énfasis en la bio- } \\
\text { diversidad, la cultura, el paisaje cafetero y los parques } \\
\text { temáticos }\end{array}$ \\
\hline
\end{tabular}

La Agenda interna de productividad y competitividad Quindío 2020, contiene las cinco apuestas productivas que el Quindío priorizó y que corresponden a los sectores de agroindustria, confecciones, turismo, software y generación de conocimientos (educación e investigación).

"La apuesta agroindustrial del Quindío incluye cultivos como el café, los cítricos y otros frutales de clima frío, el plátano y la yuca. Abarca además el desarrollo del sector forestal, tanto por medio de la producción de

11 Fuente: Departamento Nacional de Planeación (2007, 240). 
maderas -integrada a la industria de muebles y a la artesanía-, como de la comercialización de productos forestales no maderables y de la prestación de servicios ambientales (captura de CO2). Otros productos de la biodiversidad, como las flores tropicales (heliconias), los follajes exóticos y las plantas aromáticas y medicinales también están contemplados en la Agenda Interna regional" (Departamento Nacional de Planeación, 2007, 17).

En materia de agroindustria, desarrollo empresarial y agropecuario en el departamento, las acciones de la Agenda Interna fueron, entre otras: identificar, fortalecer y cooperar con las mini cadenas productivas vinculadas al sector agroindustrial; articular las mini cadenas agroindustriales y turísticas con los procesos de desarrollo tecnológico de software e implementar los acuerdos de competitividad para las cadenas productivas promisorias.

A nuestro juicio, el aspecto más importante de la Agenda Interna, cuyo ejercicio se hizo por departamentos a nivel nacional, fue el de constituirse en un insumo clave para los ejercicios de planeación posterior; pues fue allí donde se identificaron las apuestas productivas del departamento hacia un enfoque de transformación productiva para convertir las acciones que se derivaron de estas apuestas en la base de las iniciativas de proyecto -priorizadas en función de la facilidad de implementación y nivel de impacto- con presupuesto, metas y entidades responsables, fundamento del siguiente elemento de planeación regional denominado Plan regional de competitividad.

\subsection{El Plan regional de competitividad del departamento del Quindío - PRCQ, en la perspectiva de los encadenamientos productivos más promisorios del sector agroindustrial}

Este Plan consiste en un instrumento de planeación de corto, mediano y largo plazo, cuya formulación y ejecución es una tarea prioritaria de las Comisiones Regionales de Competitividad - CRC, las cuales cuentan con insumos nacionales, regionales y sectoriales para su elaboración. Dicho Plan comporta la formulación de una Visión a 2032 -tiempo que se estima necesario para transformar la estructura productiva de una región- con unos objetivos estratégicos como internacionalización, incremento de productividad y formalización, y otros transversales capaces de ayudar a consolidar la consecución de los primeros mediante soportes educativos, tecnológicos, de infraestructura, etc.

El diagnóstico de la competitividad del departamento se llevó a cabo con participación del Estado, el sector productivo y la academia, quienes al final procedieron a la identificación de las iniciativas de proyecto -algunas de ellas priorizadas como victorias tempranas por razón de su facilidad de implementación y nivel de impacto- (Gobernación del Quindío, 2009b, 53) y en materia agroindustrial dentro del objetivo estratégico, denominado "Salto a una plataforma territorial productiva, competitiva y ambientalmente sustentable". Allí se evidenció la oportunidad de participar en mercados internacionales con productos en el sector agroforestal maderables y no maderables, incluidos todos sus derivados; con siembra de cítricos, en especial la variedad sweet orange, al igual que las diversas modalidades de cafés especiales y el café tradicional (proyectos priorizados metodología establecida por el Ministerio de Comercio, Industria y Turismo y el Departamento Nacional de Planeación), a partir de la mejora continua en el proceso de optimización de su calidad en tasa. Así mismo, se presentaron iniciativas de proyecto relacionadas con la mejora en la productividad del plátano.

Como se advierte, existe una clara relación entre la Agenda Interna de Productividad y Competitividad y el Plan Regional de Competitividad (Tabla 6) en cuanto al sector agroindustrial cuando se identifican los encadenamientos productivos.

La identificación de estas iniciativas de proyecto, por estar asociadas a su integración con los mercados mundiales, exige su internacionalización; es decir, la capacidad de incorporar valor agregado a los productos identificados en el sector agroindustrial y forestal del departamento, gracias a ejercicios de innovación resultante de desarrollos aplicados en Ciencia, Innovación y Tecnología (CIT) y de conectarlos a mercados cada vez más globales. El departamento del Quindío, gracias a sus ventajas competitivas tales 
como diversidad climática, acceso a la infraestructura de transporte terrestre, una Zona Franca, el fortalecimiento de su conectividad aérea y cercanía con el occidente colombiano por vía férrea y carreteable al mar pacífico, es favorecido claramente como un centro de transformación agroindustrial y de algunos servicios especializados, con énfasis en turismo rural y en salud.

Tabla 6. Encadenamientos productivos promisorios ${ }^{12}$

\begin{tabular}{|c|c|c|c|c|c|}
\hline \multirow{2}{*}{$\begin{array}{c}\text { Documentos } \\
\text { de } \\
\text { Planeación }\end{array}$} & \multicolumn{5}{|c|}{$\begin{array}{l}\text { Productos del Sector Agroindustrial } \\
\text { en el departamento del Quindío }\end{array}$} \\
\hline & \multicolumn{5}{|c|}{ Encadenamientos identificados } \\
\hline $\begin{array}{c}\text { Agenda } \\
\text { Interna para la } \\
\text { Productividad } \\
\text { y Competi- } \\
\text { tividad del } \\
\text { Quindío }\end{array}$ & $\begin{array}{l}\text { Cafés } \\
\text { sosteni- } \\
\text { bles }\end{array}$ & $\begin{array}{l}\text { Cítri- } \\
\text { cos y } \\
\text { frutales }\end{array}$ & $\begin{array}{l}\text { Plantas } \\
\text { aromá- } \\
\text { ticas y } \\
\text { medici- } \\
\text { nales }\end{array}$ & $\begin{array}{l}\text { Plátano } \\
\text { y yuca }\end{array}$ & $\begin{array}{c}\text { Madera- } \\
\text { bles y no } \\
\text { madera- } \\
\text { bles con } \\
\text { énfasis en } \\
\text { guadua }\end{array}$ \\
\hline $\begin{array}{l}\text { Proyectos } \\
\text { priorizados } \\
\text { del PRCQ }\end{array}$ & $\begin{array}{l}\text { Cafés } \\
\text { sosteni- } \\
\text { bles }\end{array}$ & $\begin{array}{l}\text { Swetty } \\
\text { orange }\end{array}$ & & & Guadua \\
\hline $\begin{array}{c}\text { Proyectos no } \\
\text { priorizados } \\
\text { del PRCQ }\end{array}$ & & & & Plátano & \\
\hline
\end{tabular}

\subsection{La productividad y el valor agregado como presupuestos de la competitividad regional}

Para una región no basta con tener ventajas competitivas, pues la competitividad pasa directamente por el nivel de productividad obtenido en la misma, incluido por supuesto el sector agroindustrial. Al respecto, Berumen plantea, a propósito de la visión que comparten con Bradford (1994), que:

"La competitividad se le asocia con una mayor productividad, de modo que los términos competitividad y productividad se utilizan de manera indistinta, $y$ en ocasiones se entiende el concepto de competitividad como la mayor penetración en los mercados, en los crecientes flujos de inversión y en los menores costos unitarios[...] alcanzados y donde la consecuencia natural que se ha derivado del continuo e intenso cambio y aprendizaje de los países [...] es que las naciones, las regiones y las localidades compiten por segmentos de los mercados globales" (Berumen, 2006, 147).

En nuestra región es preocupante el hecho de que la estructura agrícola del departamento presente fuertes disminuciones en el cultivo del café y demás cultivos de la canasta alimentaria -identificados en los Subprogramas del Plan de Desarrollo departamental del Quindío 2008 - 2011 "Quindío unido" (Tabla 3)- a excepción del plátano, banano y otros. En efecto, al hacer una comparación de la extensión de cultivos agrícolas se evidencian cambios significativos de acuerdo al anuario estadístico del Quindío cuando se comparan las cifra de 1969, con 88.263 hectáreas sembradas y distribuidas en productos representativos de la región, frente a lo observado en los últimos años en esos mismos sectores agroindustriales (Tabla 7).

Tabla 7. Estructura agrícola del departamento del Quindío ${ }^{13}$

\begin{tabular}{|c|c|c|}
\hline \multirow{2}{*}{ Cultivos } & \multicolumn{2}{|c|}{ Cantidad de hectáreas sembradas } \\
\cline { 2 - 3 } & Año 1969 & Últimos años \\
\hline Café & 64.657 & $\downarrow 46.501$ \\
Plátano y banano & 17.069 & $\downarrow 35.095$ \\
Maíz & 2.739 & $\downarrow 1.452$ \\
Caña de azúcar & 1.374 & $\downarrow 290$ \\
Yuca & 1.078 & $\downarrow 488$ \\
Frijol & 911 & $\downarrow 550$ \\
Cacao & 244 & $\downarrow 74$ \\
Arracacha & 149 & $\downarrow 1,5$ \\
Papa & 19 & $\downarrow 26$ \\
Arveja & 17,9 & $\downarrow 12$ \\
\hline
\end{tabular}

Los cambios en la distribución de la producción departamental se han ido reflejando en el uso del suelo en el departamento porque en los últimos años se ha dado un giro relacionado con la explotación de sus recursos productivos, pasando de una vocación

12 Fuente: Plan Regional de Competitividad Quindío 2032 (2009).

13 Fuente: Gobernación del Quindío (2009a). 
agrícola exclusiva y excluyentemente cafetera a otras concentradas en los cítricos, frutales de clima frío y plátano, unido a un desarrollo importante del sector turístico (Tabla 8). Lo anterior se refleja además cuando se muestra los datos por encadenamientos productivos (Tabla 9).
Actualmente, dentro de las potencialidades del departamento del Quindío, se estima que su economía en el campo agrario y agroindustrial sigue girando en torno al cultivo del café y, además, al plátano, yuca, caña panelera, sorgo, papa, maíz y hortalizas (Ministerio de Comercio, Industria y Turismo, 2012, 11)

Tabla 8. Distribución de la producción departamental'14

\begin{tabular}{|c|c|c|c|c|c|c|}
\hline \multicolumn{2}{|c|}{ Cultivo } & $\mathbf{2 0 0 3}$ & $\mathbf{2 0 0 4}$ & $\mathbf{2 0 0 5}$ & $\mathbf{2 0 0 6}$ & $\mathbf{2 0 0 7}$ \\
\hline \multirow{3}{*}{ Café } & Producción & $65.774,00$ & $67.791,00$ & $65.281,00$ & $64.426,00$ & $63.978,00$ \\
\cline { 2 - 7 } & Porcentaje & 13,14 & 12,87 & 12,38 & 12,27 & 11,71 \\
\hline \multirow{3}{*}{ Plátano } & Producción & $312.500,4$ & $317.235,65$ & $325.814,55$ & $330.390,80$ & $334.217,27$ \\
\cline { 2 - 7 } & Porcentaje & 62,42 & 60,22 & 61,79 & 62,90 & 62,19 \\
\hline \multirow{2}{*}{ Cítricos } & Producción & $71.514,8$ & $73.122,00$ & $73.822,00$ & $78.180,50$ & $78.552,50$ \\
\cline { 2 - 7 } & Porcentaje & 14,29 & 13,88 & 14,00 & 14,89 & 14,38 \\
\hline \multirow{3}{*}{ Yuca } & Producción & $11.585,1$ & $18.522,3$ & $14.717,00$ & $6.507,00$ & $12.541,20$ \\
\cline { 2 - 7 } & Porcentaje & 2,31 & 2,31 & 2,79 & 1,24 & 2,30 \\
\hline \multirow{2}{*}{ Frutales clima frío } & Producción & $1.380,6$ & $1.128,05$ & $1.912,08$ & $1.900,33$ & $2.172,93$ \\
\cline { 2 - 7 } & Porcentaje & 0,28 & 0,21 & 0,36 & 0,36 & 0,40 \\
\hline \multirow{2}{*}{ Subtotal } & Producción & $462.754,9$ & $477.799,00$ & $481.546,63$ & $481.404,63$ & $491.461,90$ \\
\cline { 2 - 7 } & Porcentaje & 92,44 & 90,69 & 91,33 & 91,65 & 90,98 \\
\hline \multirow{2}{*}{ Otros cultivos } & Producción & $37.857,8$ & $49.020,66$ & $45.741,19$ & $43.780,71$ & $46.570,66$ \\
\cline { 2 - 7 } & Porcentaje & 7,56 & 9,31 & 8,35 & 8,35 & 9,02 \\
\hline Total 2007 & Producción & $500.612,7$ & $526.819,66$ & $525.185,34$ & $525.185,34$ & $538.032,56$ \\
\hline
\end{tabular}

Tabla 9. Promedio de la producción departamental entre 2003 y 2007 de los encadenamientos promisorios identificados $^{15}$

\begin{tabular}{|c|c|c|c|c|c|c|c|}
\hline \multicolumn{2}{|c|}{ Cultivo } & $\mathbf{2 0 0 3}$ & $\mathbf{2 0 0 4}$ & $\mathbf{2 0 0 5}$ & $\mathbf{2 0 0 6}$ & $\mathbf{2 0 0 7}$ & Promedio \\
\hline \multirow{3}{*}{ Café } & Producción & $65.774,00$ & $67.791,00$ & $65.281,00$ & $64.426,00$ & $63.978,00$ & $65.450,00$ \\
\cline { 2 - 8 } & Porcentaje & 13,14 & 12,87 & 12,38 & 12,27 & 11,71 & 12,47 \\
\hline \multirow{2}{*}{ Plátano } & Producción & $312.500,4$ & $317.235,65$ & $325.814,55$ & $330.390,80$ & $334.217,27$ & $324.031,73$ \\
\cline { 2 - 8 } & Porcentaje & 62,42 & 60,22 & 61,79 & 62,90 & 62,19 & 61,90 \\
\hline \multirow{2}{*}{ Cítricos } & Producción & $71.514,8$ & $73.122,00$ & $73.822,00$ & $78.180,50$ & $78.552,50$ & $75.032,36$ \\
\cline { 2 - 8 } & Porcentaje & 14,29 & 13,88 & 14,00 & 14,89 & 14,38 & 14,29 \\
\hline \multirow{2}{*}{$\begin{array}{c}\text { Frutales de } \\
\text { clima frío }\end{array}$} & Producción & $1.380,6$ & $1.128,05$ & $1.912,08$ & $1.900,33$ & $2.172,93$ & $1.698,80$ \\
\cline { 2 - 8 } & Porcentaje & 0,28 & 0,21 & 0,36 & 0,36 & 0,40 & 0,32 \\
\hline \multirow{2}{*}{\begin{tabular}{c} 
Otros cultivos \\
\cline { 2 - 8 }
\end{tabular}} & Producción & $37.857,8$ & $49.020,66$ & $45.741,19$ & $43.780,71$ & $46.570,66$ & $44.594,20$ \\
\cline { 2 - 8 } & Porcentaje & 7,56 & 9,31 & 8,35 & 8,35 & 9,02 & 8,58 \\
\hline
\end{tabular}

14 Fuente: Gobernación del Quindío (2009a).

15 Fuente: Gobernación del Quindío (2009a). 
(Ilustración 3). Actividades a las que se suma la prestación de servicios turísticos y productos básicos transformados aunque de manera incipiente, según se expone más adelante, en el sector de la industria alimenticia, las confecciones, productos de aseo y productos de cuero.

Dado que el concepto de competitividad está asociado directamente al de productividad, dicho indicador se redujo levemente no obstante bajar ostensiblemente el número de hectáreas sembradas, en café donde de 48.000 hectáreas se pasó en 2013 a sólo 21.000 hectáreas. En este punto la mejora en competitividad estará asociado antes que a la expansión de su siembra, al adecuado sostenimiento de las existentes y en especial al valor agregado que se le dé al producto para venderlo local e internacionalmente creando verdaderas empresas de base tecnológicas que permitan identificar nuevas rutas en la transformación del producto y su comercialización a nivel global a partir de esquemas asociativos. A nuestro juicio, este puede ser un verdadero detonante de la actividad productiva en la competitividad regional. No en vano el mismo aparece priorizado en los planes regionales como cafés especiales.

De hecho cuando se examinan los principales productos por acuerdo comercial, en el periodo enero- julio 2013, según se advierte en la tabla 10, todavía el café como producto de exportación sigue teniendo una participación predominante respecto a los demás productos agrícolas o no en nuestro departamento; incluso, en varios casos es el único producto exportado hacia destinos como Canadá, Triángulo del Norte y Mercosur. Su sostenibilidad como producto vinculado al comercio global, constituye un elemento clave a la hora de valorar la competitividad del mismo.

Igualmente, es importante considerar las grandes oportunidades que como detonante de la productividad y consecuente competitividad tiene el plátano, -incluso los cítricos- el cual puede llegar a ser un producto a incorporar más valor agregado. Ambos productos, en los términos descritos anteriormente, probablemente mejorarían el nivel de ingreso percápita en la región y por supuesto las condiciones de vida de sus habitantes.

Siendo el sector agroindustrial objeto de estudio de esta investigación, y teniendo en cuenta las ventajas competitivas y comparativas del departamento, en el PRCQ se clasifican las empresas por sector, según los resultados de la encuesta anual manufacturera, los niveles de exportaciones del Quindío, el peso en la generación de empleo y una mapificación de la cadena de agroindustria (Tabla 10).

Ilustración 3. Producción agrícola 2010 16

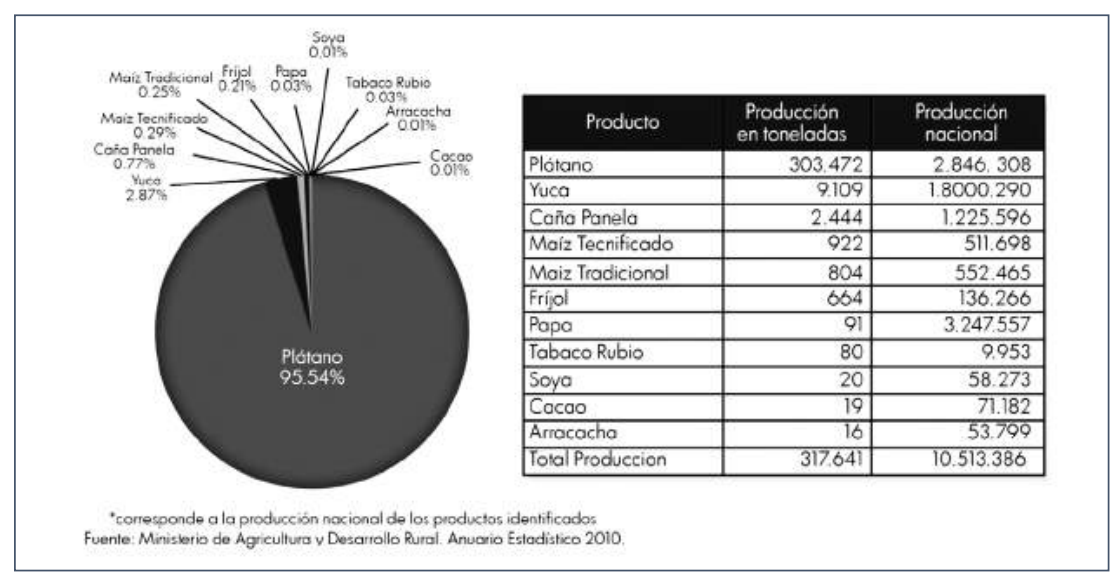

16 Fuente: Ministerio de Comercio, Industria y Turismo $(2012,3)$. 
Tabla 10. Principales productos por acuerdo comercial, en el periodo enero-julio $2013^{17}$

\begin{tabular}{|c|c|c|}
\hline Descripción & $\begin{array}{c}\text { Exportaciones enero - julio } 2013 \\
\text { miles US\$ FOB }\end{array}$ & Participación (\%) \\
\hline Total CAN & 263,6 & $100,0 \%$ \\
\hline Asientos & 118,2 & $44,8 \%$ \\
\hline Café y/otros productos del café & 90,7 & $34,4 \%$ \\
\hline Triciclos, patines & 22,5 & $8,5 \%$ \\
\hline Otras máquinas & 18,2 & $6,9 \%$ \\
\hline Preparaciones de belleza & 8,7 & $3,3 \%$ \\
\hline Tarjetas postales & 2,4 & $0,9 \%$ \\
\hline Cajas o bolsas de papel & 1,9 & $0,7 \%$ \\
\hline Tornillos & 0,9 & $0,3 \%$ \\
\hline Compresas y tampones & 0,1 & $0,04 \%$ \\
\hline Total Canadá & $8.532,9$ & $100,0 \%$ \\
\hline Café y/otros productos del café & $8.532,9$ & $100,0 \%$ \\
\hline Total Chile & 83,6 & $100,0 \%$ \\
\hline Café y/otros productos del café & 81,8 & $97,787 \%$ \\
\hline Asientos & 1,9 & $2,213 \%$ \\
\hline Total Estados Unidos & $54.207,7$ & $100,0 \%$ \\
\hline Café y/otros productos del café & $53.505,0400$ & 1,0 \\
\hline Construcciones & 328,6062 & 0,006 \\
\hline Construcciones & 162,9 & $0,003 \%$ \\
\hline Las demás manufacturas de cobre & 105,90 & $0,2 \%$ \\
\hline Aparatos de alumbrado & 69,54 & $0,1 \%$ \\
\hline Frutas u otros productos & 31,22 & $0,1 \%$ \\
\hline Demás muebles & 4,50 & $0,008 \%$ \\
\hline Extractos de café & 0,0005 & $0,0000009 \%$ \\
\hline Total MERCOSUR & 7,0 & $100,0 \%$ \\
\hline Café y/otros productos del café & 7,0 & $100,0 \%$ \\
\hline Total México & 564,9 & $100,0 \%$ \\
\hline Café y/otros productos del café & 438,8 & $77,7 \%$ \\
\hline Asientos & 126,1 & $22,3 \%$ \\
\hline Total Triángulo del Norte & 68,2 & $100,0 \%$ \\
\hline Café y/otros productos del café & 68,2 & $100,0 \%$ \\
\hline
\end{tabular}

17 Fuente: Elaborado a partir de Ministerio de Comercio, Industria y Turismo (2013b). 
Como se comentaba anteriormente, el incremento de la competitividad en estos sectores parte, en primer término, de la identificación de los diversos productos objeto del encadenamiento productivo y la posibilidad para que se les incorpore un valor agregado a través de un proceso agroindustrial (Tabla 11). Más aun, la estrategia de incorporar valor agregado aparece actualmente en términos de productos como las Buenas Prácticas Agropecuarias (BPA) y en el campo textil como las Buenas Prácticas Manufactureras, donde claramente se reflejan prácticas socialmente responsables con el ambiente y amigables con la naturaleza.

Tabla 11. Clasificación de las empresas por sector ${ }^{18}$

\begin{tabular}{|c|c|c|}
\hline Industria alimentaria & $\begin{array}{l}\text { Agroindustria no } \\
\text { alimentaria }\end{array}$ & Manufactura \\
\hline $\begin{array}{c}\text { Procesamiento de } \\
\text { plátano y yuca (snacks, } \\
\text { parafinada, etc) } \\
\text { Producción de alimentos } \\
\text { a base de café (galletas, } \\
\text { bebidas, vinos, etc) } \\
\text { Producción de cafés } \\
\text { especiales y de origen } \\
\text { Procesamiento de } \\
\text { cítricos }\end{array}$ & $\begin{array}{c}\text { Fabricación de mue- } \\
\text { bles } \\
\text { Transformación de la } \\
\text { guadua } \\
\text { Transformación de } \\
\text { cuero y productos de } \\
\text { marroquinería }\end{array}$ & $\begin{array}{l}\text { Producción de } \\
\text { medias y tejidos } \\
\text { similares } \\
\text { Producción de } \\
\text { artesanía }\end{array}$ \\
\hline
\end{tabular}

De esta manera, el mencionado valor agregado dentro de la producción industrial se identifica en un porcentaje representativo en lo que se refiere a productos alimenticios, muebles y otras industrias, productos de metal, cuero y subproductos, minerales no metálicos y prendas de vestir, lo que podría confirmar lo expuesto anteriormente en cuanto a la incipiente actividad de incorporación de valor agregado en procesos de agroindustria en el departamento del Quindío (Ilustración 4).

\subsection{Una estrategia imprescindible en la construcción de los planes y agendas departamentales: la triple hélice Universidad-Empresa-Estado}

En el Plan de Desarrollo departamental ajustado al 2009 (Sistemas Productivos Promisorios Agropecuario, Forestal y Minero en Cadenas Productivas Agropecuarias $)^{20}$, se incluyeron algunos de los encadenamientos anteriormente mencionados, razón por la cual se propuso entonces desde la visión Quindío 2032 generar:

llustración 4. Producción industrial $2009^{19}$

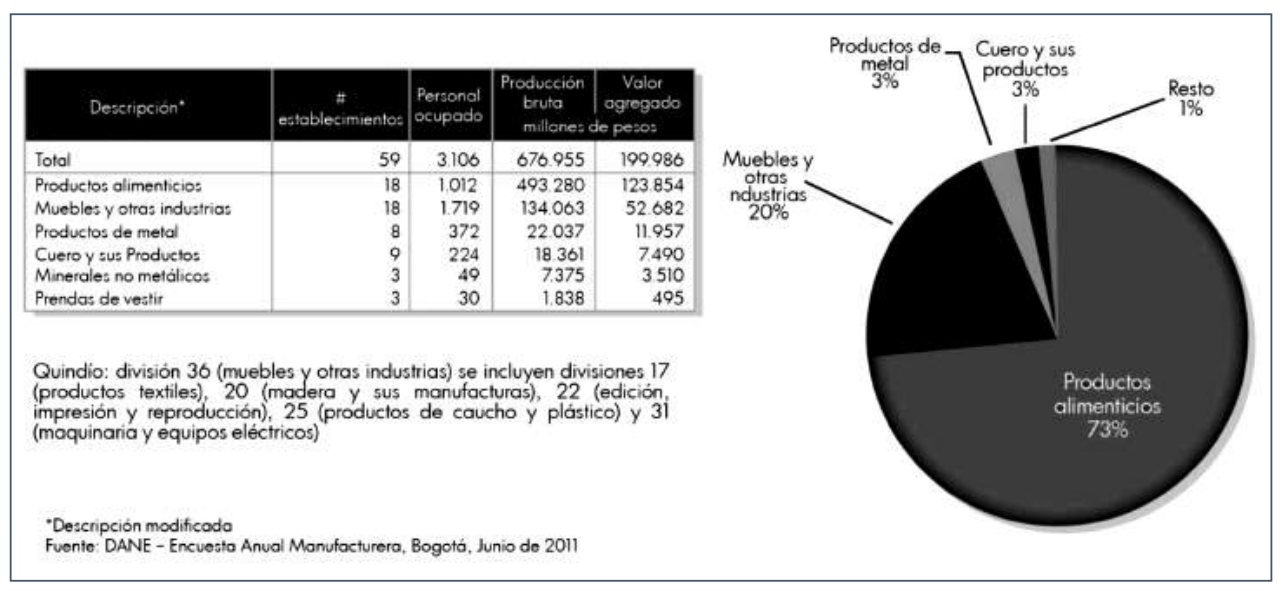

17 Fuente: Elaborada a partir de Ministerio de Comercio, Industria y Turismo (2012a).

18 Fuente: Ministerio de Comercio, Industria y Turismo (2012a, 3).

19 Se propuso apoyar el sector agrícola y pecuario a partir del encadenamiento productivo, esperando un crecimiento de la actividad agrícola y pecuaria de la región, así mismo, se establecerán nuevos convenios en el marco de agricultura por contrato, integrando nuevas asociaciones en el programa, aumentando el volumen de comercialización de la producción, así mismo el encadenamiento para la producción de cafés especiales, plátano, guadua, flores y follajes, lácteos, entre otros. Igualmente se asumió el compromiso de beneficiar con asistencia técnica a los productores con el propósito de mejorar sus productos a través del manejo de tecnologías limpias. 
"Un modelo de asociatividad e integración regional. El desarrollo de los proyectos productivos, exige un esfuerzo mancomunado, concertado y avalado por los diversos actores del departamento del Quindío, capaces de comprometer los esfuerzos técnicos, humanos y tecnológicos por parte de todos los actores involucrados en la consecución de dichos proyectos de manera que pueda lograrse una verdadera integración regional" (Gobernación del Quindío, 2009a, 31).

El objetivo es generar estrategias para enfrentar amenazas como la falta de asociatividad y confianza entre los diversos actores que participan en los ejercicios anteriormente mencionados, en especial el Estado, la Academia, la sociedad civil y el sector productivo local, donde tales dificultades no permiten generar proyectos regionales concertados de alto impacto en el departamento y en las regiones, tal y como efectivamente se ha solicitado en el nuevo Plan Nacional de Desarrollo 2010-2014:
"El enfoque de competitividad sostenida que combina elementos de competitividad externa e interna aprovecha mejor las sinergias asociadas a la participación de los actores que son centrales en el impulso a la economía local, como gobiernos locales, gremios o asociaciones de pequeños y microempresarios y ciudadanos en general" (Vargas \& Del Castillo, 2008, 69).

A continuación, un modelo simple de las debilidades y fortalezas básicas de cada uno de los actores constitutivos del desarrollo local (Ilustración 5), donde el punto de intersección muestra la posibilidad de llegar a una sinergia entre los mismos; constituyéndose así, en punta de lanza de proyectos regionales robustos y coordinados con impacto regional más que local, con verdaderas economías de escala (CEPAL, 2005, 104).

El ejercicio anterior supone, para cada uno de los sectores, generar cultura de responsabilidad social con

Ilustración 5. Interacción sector social, sector público, sector privado y sector educativo²1

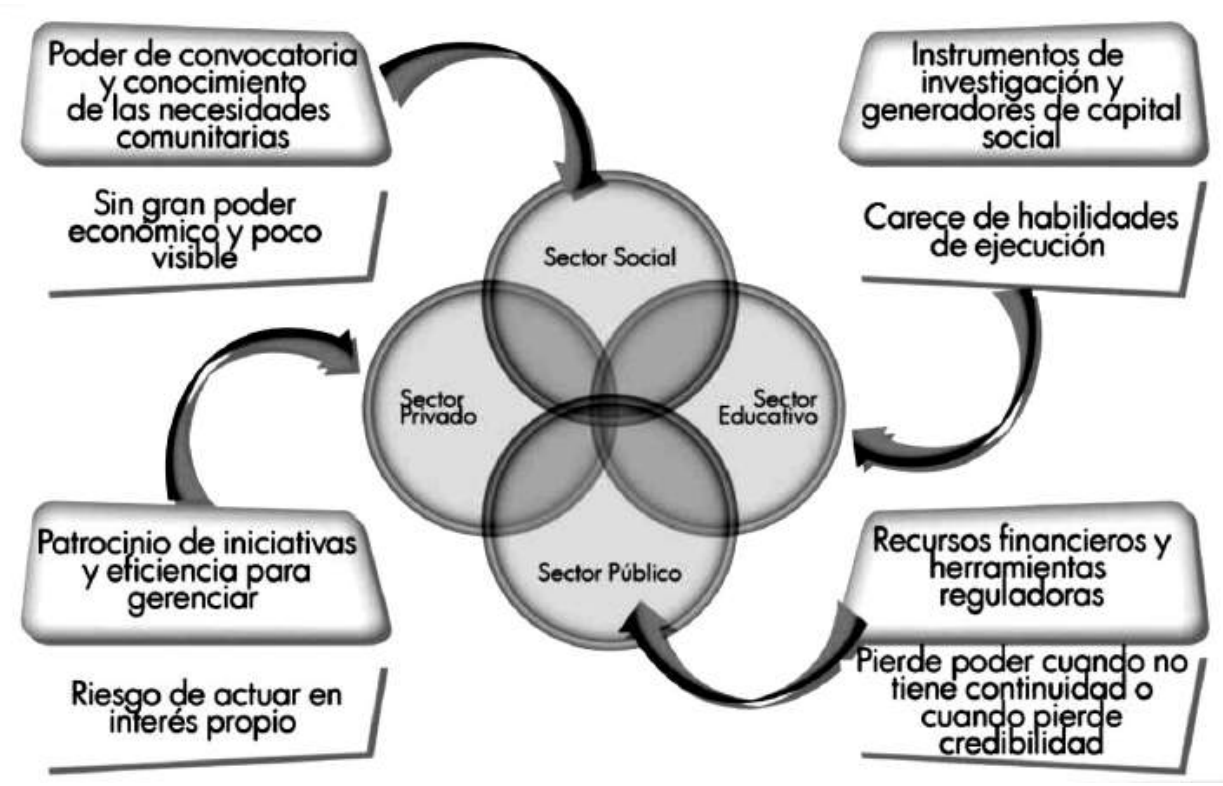

21 Plan Regional de Competitividad del departamento del Quindío (2009, 21) 
valores emergentes como la confianza, la solidaridad y la cooperación que propendan por el trabajo colectivo y la creación de cadenas globales de valor que fortalezcan el sector agroindustrial, extensivo a los demás sectores productivos en cada uno de los productos promisorios identificados en los documentos ya analizados. Y es que las cadenas globales de valor abarcan desde la investigación y desarrollo hasta el reciclaje del producto, pasando por la producción, los servicios de apoyo, la distribución, la comercialización, las finanzas y los servicios de posventa. El objetivo de estas cadenas es aumentar el contenido de conocimientos en cada una de sus etapas, ya que en ello radica el valor por unidad producida. En el debate actual sobre la competitividad aumenta entonces la importancia de los aspectos "intangibles" que más contribuyen a la intensidad de conocimientos de cada segmento de la cadena global de valor, esto es, calidad, oportunidad, conectividad, patentabilidad y registro de marcas, rastreabilidad, inocuidad, conservación ambiental y eficiencia energética (Rosales, 2009, 15).

Lo anterior nos introduce en un nuevo elemento de planeación estratégica, la consideración de la ciencia, la innovación y tecnología en el sector referido.

\subsection{Agenda departamental de Ciencia, Tecnología e Innovación}

Otro de los documentos en la formulación regional de la política pública, para la identificación de los productos agrícolas y encadenamiento de los mismos, es la Agenda departamental de Ciencia, Tecnología e Innovación. La agenda pretende generar una cultura de investigación en las entidades y la comunidad, buscando hacerlas más competitivas en la economía globalizada del conocimiento con el fin de posicionar al departamento en el ranking nacional con la inclusión del factor tecnológico, como instrumento de investigación aplicada al sector productivo. Al mismo tiempo busca promover alianzas entre universidades, centros de desarrollo tecnológico y empresas de base tecnológica, con el fin de impulsar una cultura en torno a la ciencia, la innovación y el desarrollo tecnológico a partir de la formación del recurso humano en todos sus ámbitos.

Los componentes de la Agenda son los siguientes seis sectores: educación, ambiente, salud, software, ambiente y agroindustria. Cada uno de estos sectores se compone de líneas de acción prioritarias, y estas a su vez de estrategias en las que intervienen el Estado, la academia y sector productivo, para que sea evidente la articulación de estos tres actores en el fomento de la ciencia, tecnología, innovación y desarrollo mediante la gestión y apropiación del conocimiento, el cual se resume para el departamento del Quindío en la tabla 12.

Tabla 12. Líneas de acción Agenda de Ciencia, Tecnología e Innovación ${ }^{22}$

\begin{tabular}{|c|c|c|c|c|c|}
\hline \multirow{2}{*}{$\begin{array}{l}\text { Política de } \\
\text { gobierno }\end{array}$} & \multicolumn{5}{|c|}{ Agenda de Ciencia, Tecnología e Innovación } \\
\hline & \multicolumn{5}{|c|}{ Encadenamientos identificados } \\
\hline $\begin{array}{l}\text { Subsecto- } \\
\text { res de la } \\
\text { agroindus- } \\
\quad \text { tria }\end{array}$ & Café & $\begin{array}{l}\text { Mue- } \\
\text { bles y } \\
\text { foresta- } \\
\text { les }\end{array}$ & $\begin{array}{l}\text { Cárni- } \\
\text { cos y } \\
\text { lácteos }\end{array}$ & $\begin{array}{l}\text { Hortofru- } \\
\text { tícola }\end{array}$ & $\begin{array}{l}\text { Aromá- } \\
\text { ticas y } \\
\text { medici- } \\
\text { nales }\end{array}$ \\
\hline $\begin{array}{c}\text { Sector } \\
\text { Agroin- } \\
\text { dustria y } \\
\text { Ambiente } \\
\text { - Línea } \\
\text { prioritaria }\end{array}$ & \multicolumn{5}{|c|}{$\begin{array}{c}\text { Creación de un CDTA donde interactúen las diferentes } \\
\text { entidades. Acompañado de un campo de práctica que } \\
\text { permita desarrollar investigaciones y proyectos de tipo } \\
\text { agroindustrial. }\end{array}$} \\
\hline $\begin{array}{l}\text { Línea } \\
\text { transversal }\end{array}$ & \multicolumn{5}{|c|}{$\begin{array}{c}\text { Creación del Centro de Metrología (Eje Cafetero) o Red } \\
\text { regional de metrología }\end{array}$} \\
\hline
\end{tabular}

\subsection{Plan Estratégico Departamental de Ciencia, Tecnología e Innovación PEDCTI Quindío 2022}

En concordancia con las Agendas Interna de productividad y competitividad; de Ciencia, tecnología e innovación y el Plan regional de competitividad Quindío 2032; se elaboró el Plan estratégico departamental de ciencia, tecnología e innovación del Quindío - PEDCTI Quindío 2022. La planificación prospectiva y arquitectura estratégica del PEDCTI

22 Fuente: Consejo departamental de Ciencia, Tecnología e Innovación del departamento del Quindío (2007). 
está compuesta por trece lineamientos estratégicos que comprenden programas, políticas y planes a cumplir en el corto mediano y largo plazo, cada uno con programas de investigación para su fortalecimiento de cada sector priorizado, con el propósito de consolidar la capacidad de oferta de ciencia, tecnología e innovación CTI de los sectores priorizados por este plan como son la agroindustria, el turismo y el software (OcyT, 2013).

En el sector agroindustrial, se resaltan los siguientes tres lineamientos con los respectivos programas que impactarían en términos de ciencia, tecnología e innovación (CTeI) la competitividad del Quindío al 2022 (OcyT, 2013):

(i) Articulación del sistema educativo para el desarrollo económico y social; programa:

- Investigación para el fortalecimiento del sector.

(ii) Incentivos para la formación y desarrollo de competencias científicas, tecnológicas y en gestión de la CTeI; programas:

- Formación y desarrollo de competencias científicas, tecnológicas y en gestión de la CTeI.

- Incentivos a la formación y desarrollo de capital humano.

(iii) Consolidación de la oferta productiva priorizada a través de la CTeI, de cara a los mercados globales; programas:

- Conocimiento e inversión en CTeI para la competitividad.

- Desarrollo de las apuestas agroindustriales mediante el fortalecimiento de ACTI e $\mathrm{I}+\mathrm{D}+\mathrm{i}$.

Este lineamiento se propone consolidar las apuestas productivas sustentadas en la innovación y transferencia tecnológica con talento humano formado en $\mathrm{CTeI}$, para atender las necesidades de las cadenas productivas pertenecientes al sector agroindustria a partir de las siguientes acciones como factor clave en el corto, mediano y largo plazo:

\subsubsection{Corto plazo}

- Identificar y caracterizar los negocios con enfoque de cadena para productos tales como: cafés especiales y de origen, plátano, guadua y cítricos (priorizados), en consonancia con los lineamientos derivados del Paisaje Cultural Cafetero y el ordenamiento ambiental mediante el diseño e implementación de indicadores para análisis de la cadena de valor del sector.

- Identificar e implementar procesos de investigación y transferencia tecnológica para los negocios con enfoque de cadena.

- Identificar y caracterizar las capacidades, infraestructura y equipos en CTeI para cafés especiales y de origen, plátano, guadua y cítricos.

- Promover el modelo organizacional de las líneas de negocio de los encadenamientos productivos de cafés especiales y de origen, plátano, guadua y cítricos.

- Estructurar la oferta de servicios de investigación y transferencia tecnológica de las instituciones de educación superior, para que responda efectivamente a las agendas de las instituciones del entorno organizacional de soporte y fomento de las cadenas productivas de cafés especiales y de origen, plátano, guadua y cítricos.

- Implementar nuevos modelos y metodologías de extensión universitaria y proyección social que integren el sector productivo de los encadenamientos productivos agroindustriales priorizados.

\subsubsection{Mediano plazo}

- Identificar, caracterizar e implementar sistemas y procesos de logística para las líneas de negocio de las cadenas productivas de cafés especiales y de origen, plátano, guadua y cítricos. 
- Diseñar y poner en marcha un sistema de inteligencia de negocios y vigilancia tecnológica para los productos de los encadenamientos priorizados.

- Implementar el Centro de Desarrollo Tecnológico Agroindustrial con especial énfasis en las cadenas productivas de cafés especiales y de origen, plátano, guadua y cítricos.

\section{Resultados}

Resultado del análisis de los Planes y Agendas departamentales y los referentes nacionales, se procede a identificar los cinco encadenamientos más promisorios en el departamento del Quindío, los cuales aparecen reflejados en la tabla 13 y representados en la Ilustración 6.

A continuación se presentan los encadenamientos más promisorios en el sector agroindustrial por municipio en el departamento del Quindío. Se advierten variaciones en el eje vertical dadas las diferencias en los encadenamientos de cada uno de los productos agrícolas en los distintos municipios que constituyen el departamento del Quindío (Ilustración 7).

Como se observa, el análisis de políticas nacionales y departamentales permitió identificar los cinco encadenamientos más promisorios del sector agroindustrial en el departamento del Quindío como son café, plátano, guadua, frutales de clima cálido y frío, y plantas aromáticas y medicinales. Así mismo, su alineación con la política nacional - Ministerios de Comercio Industria y Turismo MCIT y de Agricultura y Desarrollo Rural MADR-, vía encadenamientos y planes nacionales, pone de presente el nivel de coherencia y de oportunidades que hoy existe en los mencionados encadenamientos regionales. Finalmente, la aplicación de la Ciencia, Innovación y Tecnología en la respectiva agenda local a dichos encadenamientos productivos revela grandes potencialidades pero también grandes retos para el departamento de cara a su integración en los mercados mundiales en productos con alto valor agregado, de acuerdo a lo visto en la Ilustración 5 . Nuestro análisis permitió también desde los mismos municipios del departamento focalizar los tipos de encadenamientos referidos.

\section{Conclusiones}

La apertura de los mercados en la que ha venido trabajando el país, mediante tratados de libre comercio y otras formas de integración, supone para Colombia a dos años el acceso a más de mil quinientos millones de consumidores -según datos del MCIT aquí citado- y cuyo aprovechamiento dependerá, en buena medida, del nivel de integración internacional de los productos y sus encadenamientos agroindustriales locales de cara a los mercados globales.

Respecto a las condiciones de medio geográfico, la connurbación del territorio del departamento del Quindío trae grandes fortalezas en términos de ventajas competitivas; más la real importancia de esta región radica en los aportes que cada una de las ciudades y poblaciones que la conforman pueden brindar para el logro de una adecuada complementariedad resultante de su proximidad funcional en materia de prestación de servicios y vocaciones territoriales de sus municipios; permitiéndole identificar el papel que cada una de ellas realice en función de su objetivo en la región y cómo a partir de este enfoque llegar a formular políticas regionales de competitividad; lo que, sin duda, no ha sido fácil $y$ en consecuencia, constituye un gran reto para sus líderes y toda la región connurbada.

Desde el orden local en el departamento del Quindío, y a partir de directrices nacionales, se llevó a cabo la construcción de importantes instrumentos de planeación tales como la Agenda Interna de Productividad y Competitividad, el Plan Regional de Competitividad y otros más descritos en el artículo-ejercicios que fueron de carácter nacional en todas las regiones y departamentos- en los cuales se identificó la focalización de las apuestas regionales con sus iniciativas de proyectos a desarrollar en el marco de la Teoría de la Triple Hélice: Universidad- Empresa-Estado como una de las claves en los desarrollos locales y donde las regiones enfrentan grandes retos para su ejecución.

La priorización y focalización en los ejercicios de planeación económica regional, exigen el diseño de políticas que tiendan a un incremento en la productividad y por lo tanto en la mejora regional de los 
Tabla 13. Definición de encadenamientos promisorios ${ }^{23}$

\begin{tabular}{|c|c|c|c|c|c|c|}
\hline Políticas de Gobierno & 1 & 2 & 3 & 4 & 5 & Otros \\
\hline $\begin{array}{l}\text { Agenda Interna de } \\
\text { Productividad y } \\
\text { Competitividad }\end{array}$ & Plátano y yuca & $\begin{array}{l}\text { Cítricos y } \\
\text { frutales }\end{array}$ & $\begin{array}{c}\text { Plantas aromáticas y } \\
\text { medicinales }\end{array}$ & $\begin{array}{l}\text { Maderables } \\
\text { y no } \\
\text { maderables } \\
\text { con énfasis en } \\
\quad \text { guadua }\end{array}$ & $\begin{array}{c}\text { Cafés } \\
\text { sostenibles }\end{array}$ & \\
\hline $\begin{array}{l}\text { Plan Regional de } \\
\text { Competitividad }\end{array}$ & & $\begin{array}{l}\text { Swetty } \\
\text { orange }\end{array}$ & & Guadua & $\begin{array}{c}\text { Cafés } \\
\text { sostenibles }\end{array}$ & \\
\hline $\begin{array}{l}\text { Agenda de Ciencia, } \\
\text { Tecnología e Innovación }\end{array}$ & & & Aromáticas y medicinales & $\begin{array}{l}\text { Guadua, } \\
\text { Muebles y } \\
\text { forestales }\end{array}$ & Café & $\begin{array}{l}\text { Cárnicos, lácteos y } \\
\text { hortofrutícola }\end{array}$ \\
\hline PEDCTI & Plátano & Cítricos & & Guadua & Cafés especiales & \\
\hline $\begin{array}{l}\text { Plan de Desarrollo } \\
\text { Departamental } \\
2008-2011\end{array}$ & Plátano & $\begin{array}{l}\text { Frutales de } \\
\text { clima frío y } \\
\text { cálido }\end{array}$ & $\begin{array}{l}\text { Hierbas aromáticas y } \\
\text { medicinales }\end{array}$ & Guadua & Cafés especiales & $\begin{array}{c}\text { Caña, lácteos y granos } \\
\text { Flores y follajes } \\
\text { exóticos Hortalizas y } \\
\text { verduras }\end{array}$ \\
\hline $\begin{array}{c}\text { Análisis gestión } \\
\text { Secretaría de Desarrollo } \\
\text { Económico, Rural y } \\
\text { Ambiental }\end{array}$ & Plátano & Mora & Plantas medicinales & Guadua & Café & $\begin{array}{l}\text { Caña Lácteos, frijol } \\
\text { Hortalizas y maíz }\end{array}$ \\
\hline $\begin{array}{l}\text { Ministerio de Agricultura } \\
\text { y Desarrollo Rural }\end{array}$ & $\begin{array}{l}\text { Cadena del } \\
\text { Plátano }\end{array}$ & $\begin{array}{l}\text { Cadena de } \\
\text { los cítricos }\end{array}$ & Cadena de Plantas Aromáticas & $\begin{array}{l}\text { Cadena } \\
\text { Guadua y su } \\
\text { Industria }\end{array}$ & & \\
\hline $\begin{array}{l}\text { Plan de Desarrollo } \\
\text { Departamental } \\
2012-2015\end{array}$ & $\begin{array}{l}\text { Cadena del } \\
\text { Plátano }\end{array}$ & $\begin{array}{l}\text { Cadena de } \\
\text { los cítricos }\end{array}$ & Cadena de Plantas Aromáticas & $\begin{array}{l}\text { Cadena } \\
\text { Guadua y su } \\
\text { Industria }\end{array}$ & & $\begin{array}{c}\text { Encadenamientos } \\
\text { productivos } \\
\text { enmarcados dentro de } \\
\text { las cadenas productivas } \\
\text { reconocidas por } \\
\text { el Ministerio de } \\
\text { Agricultura y Desarrollo } \\
\text { Rural }\end{array}$ \\
\hline $\begin{array}{l}\text { Ministerio de Comercio, } \\
\text { Industria y Turismo } \\
\text { - Programa Nacional } \\
\text { de transformación } \\
\text { productiva - }\end{array}$ & & & & & & $\begin{array}{c}\text { Cacao, confitería y } \\
\text { chocolatería, palma, } \\
\text { aceites y grasas, } \\
\text { camaronicultura, } \\
\text { cárnico y } \\
\text { biocombustible }\end{array}$ \\
\hline $\begin{array}{l}\text { Agenda nacional de } \\
\text { competitividad }\end{array}$ & & & & & & $\begin{array}{c}\text { Camaronicultura; } \\
\text { chocolatería, confitería } \\
\text { y sus materias primas; } \\
\text { carne bovina; palmas, } \\
\text { aceites y grasas } \\
\text { vegetales }\end{array}$ \\
\hline
\end{tabular}

${ }^{23}$ Fuente: Los autores. 
Ilustración 6. Planes y Agendas departamentales para la identificación de encadenamientos promisorios ${ }^{24}$

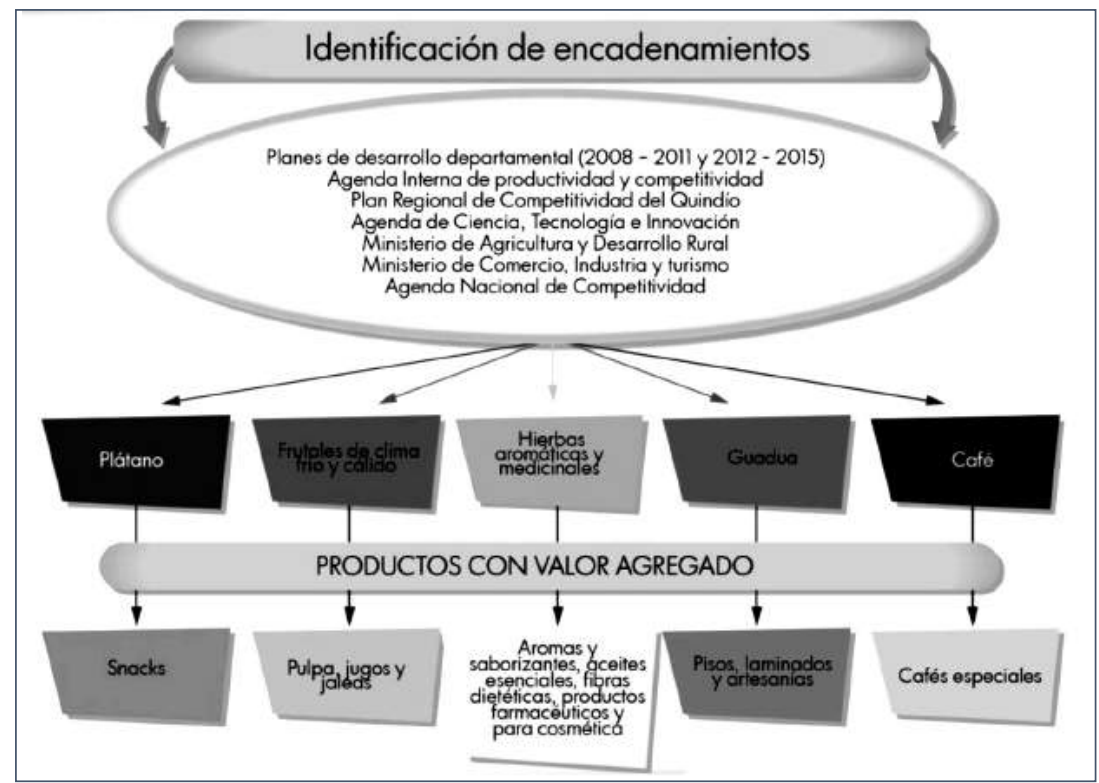

Ilustración 7. Distribución de encadenamientos más promisorios en el sector agroindustrial por cada municipio del departamento del Quindío²5

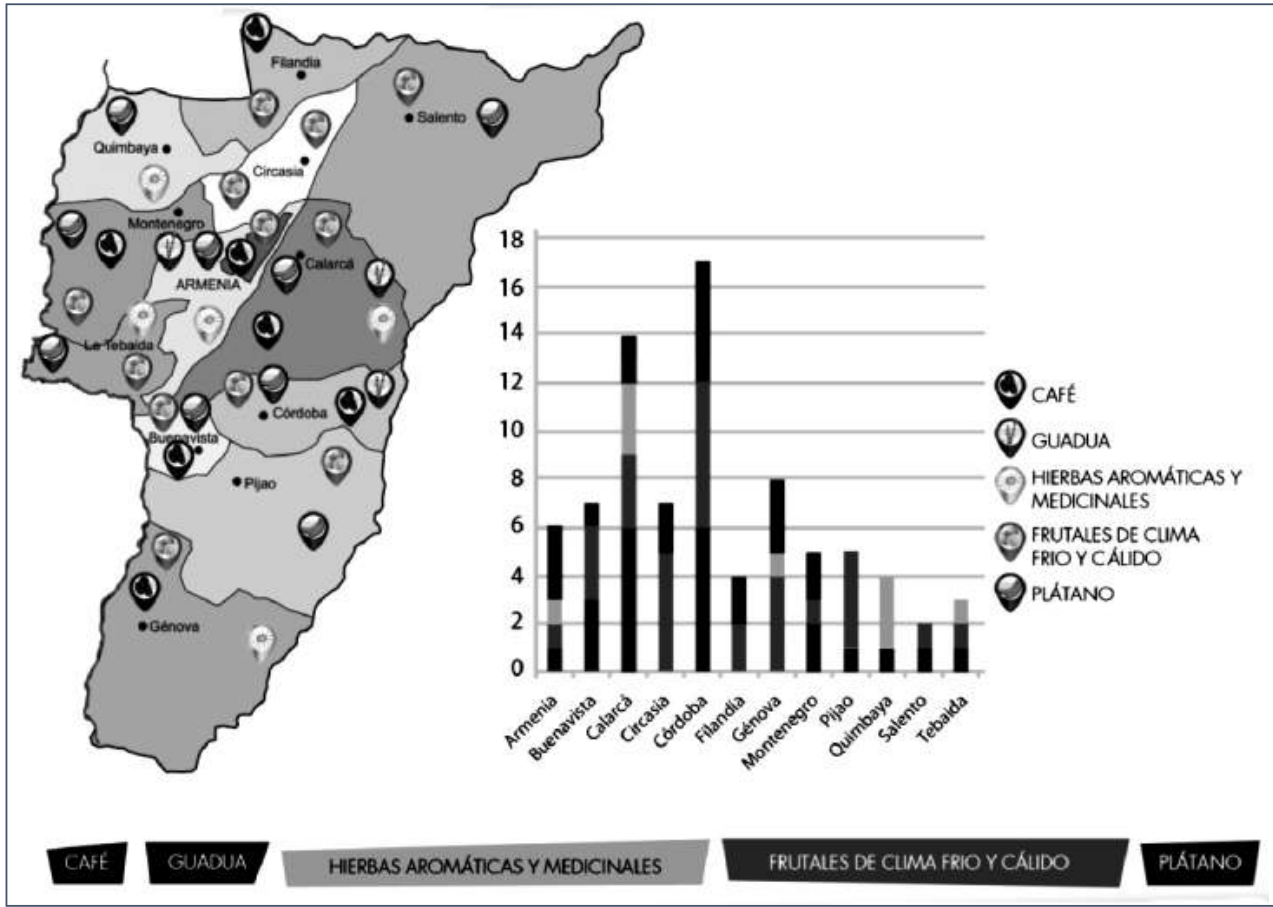

24 Fuente: Los autores.

25 Fuente: Los autores. 


\section{IDENTIFICACIÓN DE LOS ENCADENAMIENTOS MÁS PROMISORIOS DEL SECTOR AGROINDUSTRIAL \\ DEL DEPARTAMENTO DEL QUINDÍO (COLOMBIA)}

niveles competitivos en el sector referido -cuyos indicadores no han mejorado en el departamento del Quindío- al igual que en la incorporación de valor agregado a los productos agrícolas locales de manera que podamos constituirlos como verdaderos sectores de "Clase mundial".

En este sentido, en el artículo se exponen cuáles serían los encadenamientos más promisorios en el departamento del Quindío y, por lo mismo, con altas posibilidades que podrían ser potencializadas desde el Gobierno central. Solo así es posible una verdadera integración a los mercados globales, pues como bien dice Michael Porter, es en las regiones donde nace la Competitividad.

El artículo, igualmente, pone de presente los grandes retos del MCIT y demás entidades suscritas al mismo como BANCOLDEX, PROEXPORT y demás, para crear e impulsar nuevos sectores de clase mundial de carácter agrícola y agroindustrial, pues muchos de los existentes a nivel regional no aparecen priorizados en los Programas nacionales -excepto en los encadenamientos productivos del MADR- en particular en el programa de transformación productiva; con lo cual, al menos para el departamento del Quindío, muchos de los esfuerzos locales se ven diseminados a la hora de evaluar su conexión con los diseños de la política en el orden nacional e institucional, en un sector particularmente sensible a la competencia global.

\section{Referencias}

Berumen, S. (2006). Una aproximación a los indicadores de la competitividad local y factores de la producción. En: Cuadernos de administración, Pontificia Universidad Javeriana, 19(31): 145-163.

Bradford, B. I. (1994). The new paradigm of systemic competitiveness: Toward more integrated policies in Latin America. París: OECD.

Consejo departamental de Ciencia y Tecnología del Quindío [CODECYT] (2007). Agenda de ciencia, tecnología e innovación. Armenia.

Consejo Nacional de Política Económica y Social República de Colombia - CONPES (2008). Documento Conpes 3668. Informe de seguimiento a la política nacional de competitividad y productividad. Ley 1253 de 2008. Bogotá, D. C.. Recuperado el 30 de septiembre de 2012, de http:// wsp.presidencia.gov.co/sncei/politica/Documents/Conpes3668-28jun2010.pdf

Consejo Privado de Competitividad Colombia - CONPES (2011). Informe nacional de competitividad - Ruta a la prosperidad colectiva 2011 - 2012. Recuperado el 18 de octubre de 2012, de http://www.compite.com.co/site/wp-content/uploads/2011/11/ INC2011-2012.pdf

Corporación Autónoma Regional del Quindío - CRQ (2010). Determinantes Ambientales para el Ordenamiento Territorial municipal en el Departamento del Quindío. Oficina asesora de planeación y direccionamiento estratégico. Recuperado el 27 de marzo de 2014. Disponible en: http://www.crq.gov. co/Documentos/SIGAM/Determinantes\%20Ambientales.pdf.

Corporación Autónoma Regional del Quindío CRQ. (2004). Mapa de zonificación por aptitud forestal - departamento del Quindío. Recuperado el 27 de marzo de 2014. Disponible en: http://200.21.93.53/ArchivosQuindioII/SIG_QUINDIO/MAPOTECA/AMBIENTAL/zonificacion Forestal.pdf

Díaz, S. (2012). Los Acuerdos de Libre Comercio: oportunidades para los comerciantes colombianos. En Congreso Nacional FENALCO, Armenia, Colombia.

Diez, L. (2003). Cadenas productivas: Una alternativa para afrontar la integración regional. En: Cuadernos de Difusión, ESAN, 8(14): 113-120.

Departamento Nacional de Planeación (2007). Plataforma de agroindustria como factor de desarrollo. Recuperado en 2010. Disponible en: http://www.quindio.gov.co/home/docs/general/ PLAN\%20DESARROLLO\%20QUINDIO\%20UNIDO.pdf

Gobernación del Quindío (2009a). Recepción de proyectos productivos para participar en convocatoria auspiciada por el gobierno alemán. En: Boletines Quindío rural 2009. No. 32. Recuperado el 24 de mayo de 2009. Disponible en: http:// www.quindiorural.gov.co/

Gobernación del Quindío (2009b). Plan regional de competitividad del departamento del Quindío [PRCQ]. Armenia.

Gobernación del Quindío (2012). Plan de Desarrollo Departamental 2012 - 2015 "Gobierno firme por un Quindío más humano". Ordenanza No. 018 de Mayo 30 de 2012. Armenia: Gobernación del Quindío.

Grobart, F. (2003). Innovación, competitividad, globalización: Políticas de la OCDE y de América Latina en los años noventa. En: Economía y Desarrollo, Universidad Autónoma de Colombia, 36 (1).

Londoño, I. \& Sánchez, L. (2009) Diagnóstico del grado de asociatividad de los agentes que intervienen en las cinco cadenas de valor más promisorias del sector agroindustrial del departamento del Quindío. Armenia: Fundación Escuela de Administración y Mercadotecnia del Quindío.

Ministerio de Industria y Comercio (2012). "Perfil económico del departamento del Quindío". Disponible en: http://www.mincit. gov.co/publicaciones.php?id $=16724$

Ministerio de Industria y Comercio (2013). a) Quindío frente a los acuerdos comerciales en curso. Oficina de estudios económicos.

Ministerio de Industria y Comercio (2013). b) Exportaciones - principales productos por acuerdo comercial.

Observatorio Colombiano de Ciencia y Tecnología - OcyT (2013). Plan Estratégico Departamental de Ciencia, Tecnología e Innovación PEDCTI QUINDÍO 2022: Eje de ciencia, tecnología e innovación regional en el Paisaje Cultural Cafetero. Primera Edición 2013. Bogotá

Plan Nacional de Desarrollo (2006-2010). "Estado Comunitario: desarrollo para todos". Disponible en: https://www.dnp.gov. co/LinkClick.aspx?fileticket $=$ WSgQTUkodjQ\%3d\&tabid $=65$.

Plan Nacional de Desarrollo (2010-2014). "Prosperidad para todos". Disponible en: https://www.dnp.gov.co/PND/PND20102014.aspx. 
Plan Regional de competitividad Quindío-2032 (2009). Documento del Ministerio de Industria y comercio. Disponible en: http:// www.comisionesregionales.gov.co/publicaciones.php?id $=928$

Porter, M. (2005) ¿Qué es la competitividad? ESE Business School - Centro Anselmo Rubiralta de Globalización y Estrategia. Universidad de Navarra. Recuperado el 27 de marzo de 2014. Disponible en: http://www.iese.edu/es/ad/anselmorubiralta/ apuntes/Competitividad_es.html

Rosales, O. (2009). La globālización y los nuevos escenarios del comercio internacional. En: Revista CEPAL, 97.

Valencia, F. (2008). Alianzas Público-Privadas para la competitividad - Sistema Nacional de Competitividad Colombia. Conferencia presentada en Medellín, Colombia.
Vargas, B. \& Del Castillo, C. (2011). Competitividad sostenible de la pequeña empresa: un modelo de promoción de capacidades endógenas para promover ventajas competitivas sostenibles y alta productividad. En: Cuadernos de Difusión, Universidad ESAN, 13(24): 59-79.

Visión País 2019 y 2032. Disponible en: https:/www.dnp.gov.co/ PolíticasdeEstado/VisiónColombia2019.aspx.

Wong, P. (2005). La emergencia de regiones asociativas transfronterizas cooperación y conflicto en la región Sonora-Arizona. En: Frontera Norte, 17(33): 77-106. 